\title{
Links between behaviour change techniques and mechanisms of action: an expert consensus study
}

Lauren E. Connell ${ }^{1,5}(\mathrm{PhD})$, Rachel N. Carey $^{1}(\mathrm{PhD})$, Marijn de Bruin ${ }^{2}(\mathrm{PhD})$, Alexander J. Rothman $^{3}(\mathrm{PhD})$, Marie Johnston ${ }^{2}(\mathrm{PhD})$, Michael P. Kelly ${ }^{4}(\mathrm{PhD}) \&$ Susan $_{\text {Michie }^{*}}(\mathrm{PhD})$

${ }^{1}$ University College London; Centre for Behaviour Change, University College London, 1-19 Torrington Place, London, WC1E 7HB, UK

${ }^{2}$ University of Aberdeen; Aberdeen Health Psychology Group, Institute of Applied Health Sciences, Health Sciences Building, Foresterhill, Aberdeen, AB25 2ZD, UK

${ }^{3}$ University of Minnesota; Department of Psychology, 75 East River Road, Minneapolis, MN 55455, USA.

${ }^{4}$ Primary Care Unit, Institute of Public Health, University of Cambridge, Forvie Site, Cambridge, CB2 0SR, UK.

${ }^{5}$ Department of Kinesiology, University of Rhode Island, 25 W Independence Way, Kingston, RI 02881, USA

*Corresponding Author is Susan Michie, Centre for Behaviour Change, University College London, 1-19 Torrington Place, London WC1E 7HB; E-mail: s.michie@ucl.ac.uk Funding

This research is funded by UK Medical Research Council grant number MR/L011115/1.

Word Count: 6,061 (Excluding abstract and references) 


\begin{abstract}
BACKGROUND: Understanding the mechanisms through which behaviour change techniques (BCTs) can modify behaviour is important for the development and evaluation of effective behavioural interventions. To advance the field, we require a shared knowledge of the mechanisms of action (MoAs) through which BCTs may operate when influencing behaviour.
\end{abstract}

PURPOSE: To elicit expert consensus on links between BCTs and MoAs.

METHODS: In a modified Nominal Group Technique study, 105 international behaviour change experts rated, discussed, and re-rated links between 61 frequently used BCTs and 26 MoAs. The criterion for consensus was that at least $80 \%$ of experts reached agreement about a link. Heat maps were used to present the data relating to all possible links.

RESULTS: Of 1,586 possible links (61 BCTs $\times 26$ MoAs), 51 of 61 (83.6\%) BCTs had a definite link to one or more MoAs (mean $(S D)=1.44(0.96)$, range= 1-4), and 20 of 26 (76.9\%) MoAs had a definite link to one or more BCTs (mean $(S D)=3.27(2.91)$, range=9). Ninety (5.7\%) were identified as 'definite’ links, 464 (29.2\%) as ‘definitely not' links, and 1032 (65.1\%) as ‘possible’ or ‘unsure’ links. No ‘definite’ links were identified for 10 BCTs (e.g. 'Action Planning' and 'Behavioural Substitution’) and for six MoAs (e.g. 'Needs' and 'Optimism’).

CONCLUSIONS: The matrix of links between BCTs and MoAs provides a basis for those developing and synthesizing behavioural interventions. These links also provide a framework for specifying empirical tests in future studies. 
Links between behaviour change techniques and mechanisms of action: an expert consensus study

Behaviour change interventions have the potential to improve health, reduce premature mortality (1), disability (2), and health care expenditures (3). To achieve this, effective interventions that lead to sustained behaviour change are needed (4). Given the complexity of behaviour change interventions, it is important to identify the potentially active ingredients within an intervention (i.e. behaviour change techniques (BCTs)), the processes through which behaviour change occurs (i.e. the 'mechanisms of action' (MoAs)), and the links between BCTs and MoAs. The potentially active ingredients (BCTs) in an intervention are those aspects of an intervention which produce a change in behaviour. The BCTs produce a change in behaviour by acting upon a process (e.g. a psychological, physical, or social process) which changes as a result of the active ingredient, this change is what catalyses a change in behaviour. We define MoAs as processes which influence behaviour. We define a BCT-MoA link as a pathway through which behaviour change occurs, via a specific BCT producing change in a specific MoA. An improved understanding of the links between BCTs and MoAs can facilitate the development of more effective interventions, and improve the ability to explain how effective interventions bring about change.

Behavioural science has made substantial progress in harmonising and standardising the reporting of interventions (5-9) and their theoretical underpinnings (10-12), which facilitates communication across disciplines and supports intervention replication and implementation. Intervention reporting has been enhanced through the development of methods to describe potentially active ingredients within interventions systematically $(7,13)$, thereby facilitating knowledge accumulation across different interventions. The 93-item Behaviour Change Technique v1 Taxonomy, for example, was developed with contributions from a large international network of behaviour change experts, and is a formal and 
standardised classification system of labels and definitions of these intervention techniques (i.e. which potentially active ingredients are delivered within an intervention) (7). To date, the BCT v1 Taxonomy has been used across a wide range of behavioural domains to specify content for intervention reports, to aid in intervention design, and to synthesise information across intervention evaluations (see http://www.bct-taxonomy.com/interventions for a searchable database of over 350 articles reporting interventions coded by BCTs.

The BCT v1 Taxonomy provides a shared language with which to describe intervention content (i.e. BCTs); however, it does not directly specify which MoAs these BCTs target. The importance of understanding the links between MoAs and BCTs is highlighted in frameworks for the development of behaviour change interventions [e.g., Intervention Mapping (9), Precede-Proceed (14), Behaviour Change Wheel (15)]. Identifying specific links is important in developing interventions and understanding the process through which behaviour change may occur, as emphasised by the Cochrane Collaboration's Effective Practice and Organisation of Care (EPOC) Group (16), and from The National Institute for Health and Care Excellence's (NICE) Public Health guidelines in the UK (17, 18). In the United States, the Science of Behavior Change initiative has also highlighted this need, and is building knowledge in this area by experimentally testing methods for changing specified MoAs (see https://commonfund.nih.gov/behaviorchange/index).

There are direct ways of generating evidence on how BCTs and MoAs are linked, namely experimental studies and meta-analyses thereof (19). However, currently available evidence is insufficient to do that for a large number of BCTs and MoAs. There are also several indirect approaches that allow for exploring how a larger set of BCTs and MoAs are linked. One way to infer how BCTs are related to MoAs is to investigate links between BCTs and MoAs explicitly hypothesised in the published intervention literature (see Carey et al. under review). Although the published literature provides valuable information, it is limited 
by what research has been funded, which findings have been published, and what researchers choose to report. A complementary source of evidence is the current thinking of international experts in behaviour change. This source of information encompasses the existing hypotheses of experts in the field, which are unhindered by publication and funding constraints, yet also informed by existing theory and evidence, including evidence from current research. One method of examining experts' hypotheses is through expert consensus methodology.

Expert consensus methods can be used to facilitate the development of research questions, solutions to existing problems, and priorities for action (20). They enable differing ideas on topics of mutual interest to be discussed, reported and organised, with a view to establishing areas of consensus and priorities for further investigation. Participation in this approach also tends to foster the participants' ownership of the resulting research and thus increases the likelihood of changing future practice and research (21).

This study is one of four in a programme of research to develop and test a methodology for linking BCTs to MoAs (see (22) for the protocol). The aim of the current study is to develop - based on expert consensus - an overview of the mechanisms through which BCTs might alter behaviour. Specific questions are: (1) Through which MoAs do experts agree BCTs influence behaviour? (2) Through which MoAs do experts agree BCTs do not influence behaviour? (3) How specific are the mechanisms through which BCTs have an effect, i.e., do experts agree BCTs influence behaviour through one MoA or that they can influence behaviour through multiple MoAs? Subsidiary questions are: (4) About which links between MoAs and BCTs do experts disagree? (5) Can all BCTs be linked to at least one MoA? and (6) Can all MoAs be linked to at least one BCT?

\section{Methods}

\section{Design}


Expert consensus about links between BCTs and MoAs were investigated using a formal consensus method drawing on Nominal Group Technique (NGT) (23) in three rounds: (i) an initial rating round, (ii) a discussion round, and (iii) a final rating round.

\section{Participants}

Participants were experts with experience in designing, evaluating and/or synthesising evidence about theory-based behaviour change interventions selected to represent a range of countries, professional backgrounds, and academic disciplines.

Recruitment. An invitation email describing the study was sent to (i) those who had participated in BCT training (online BCT Taxonomy training (http://www.bcttaxonomy.com/), in-person BCT training workshops, or the BCT Taxonomy v1 project (8; http://www.ucl.ac.uk/health-psychology/bcttaxonomy), (ii) members of the project's International Advisory Board, and (iii) email lists maintained by scientific and professional societies and centres (University College London’s Centre for Behaviour Change, the Special Interest Group of the Society of Behavioral Medicine, European Health Psychology Society, United Kingdom Society for Behavioural Medicine, and Division of Health Psychology of the British Psychological Society). Using a 'snowballing' method, those recruited were asked to recommend other experts for recruitment into the study.

Those expressing interest in becoming an expert judge $(n=227)$ completed a selfassessment questionnaire (see Appendix A) to evaluate their experience and expertise in behaviour change interventions. To be eligible to participate in the study, experts needed to both (i) rate their expertise as $\geq 4$ (on a 7-point scale, where 0 indicates 'No expertise' and 7 indicates 'Profound Expertise') in BCTs, behaviour change theories, and behaviour change interventions; and (ii) report having some experience designing or helping to design behaviour change intervention(s) that 'used specific BCTs' and 'was specifically grounded in behaviour change theory/theories'. Based on these inclusion criteria, 123/227 (54.2\%) of the 
interested participants were eligible. We sent these 123 experts a second questionnaire, seeking information to help recruit experts across a range of countries, professional backgrounds, and academic disciplines (see Appendices B-C).

Our final sample included 105 experts which was sufficient to provide task subgroups of at least 20 experts - a number found in previous work to demonstrate stability of consensus (24). Nearly 50\% of experts were from the United Kingdom, 20\% were from other countries in Europe, 20\% from North America, and 10\% of experts were from Africa, and Australia/New Zealand. Most experts worked in a university setting (75\%), in the field of psychology (60\%). Additional descriptive information about the experts' backgrounds is depicted in Figure 1, and information about the experts' self-rated expertise in behaviour change theory, interventions, and techniques is located in Appendix C.

\section{[INSERT FIGURE 1]}

\section{Procedure}

Expert ratings for Rounds 1 and 3 were given via Qualtrics (25), a web-based software for administering surveys; the expert discussion in Round 2 was managed via the online forum 'Loomio' (26). In Rounds 1 and 3, experts rated links between a discrete set of BCTs and MoAs. In order to reduce participant burden, we limited the number of BCTs and MoAs included in the study based on the following criteria: (a) BCTs had to be commonly used within the intervention literature, therefore we selected only those BCTs identified more than twice ( $\mathrm{n}=61)$ in a set of 40 systematically identified and coded intervention descriptions covering a range of different behaviours (27); (b) MoAs were restricted to those contained within (i) the 14 theoretical domains described in the Theoretical Domains Framework (28) and (ii) the 12 most frequently occurring MoAs (which did not overlap with the Theoretical Domains Framework) identified in a systematic review of 83 behaviour change theories (29). This resulted in 61 BCTs and 26 MoAs. A full list of the MoAs and their definitions is 
provided in Table 1. In order to ensure the task was manageable for experts, we divided the BCTs into five groups and allocated either 13 or 14 BCTs x 26 MoAs (i.e., 338 or 364 possible links) for judgement by each group of experts. We block-randomised the 105 experts to one of five groups, with 21 experts per group, distributing experts from different countries, professional backgrounds, and academic disciplines among the five groups. To reduce possible bias in group ratings due to varying levels of familiarity with BCTs, BCTs were ordered according to the frequency with which they were used in interventions (8), and allocated to each of the five expert groups through stratified random allocation. Information about which BCTs were rated by each of the five groups is in Appendix D.

\section{[INSERT TABLE 1 AROUND THIS SECTION]}

\section{Conduct of the consensus exercise.}

Round 1: Initial ratings of BCT $\boldsymbol{x}$ MoA links. The aim of Round 1 was to establish an initial level of consensus among experts for each BCT x MoA link. For each of the 13 or 14 assigned BCTs, experts responded to the question, "Does the Behaviour Change Technique [e.g., Goal Setting] change behaviour through the MoA [e.g. beliefs about one’s ability to successfully carry out a behaviour (Beliefs about Capabilities)]?” on a 5-point scale (Definitely No, Probably No, Don’t Know/Uncertain, Probably Yes, Definitely Yes). For each BCT, the 26 MoAs were randomised to appear in a different order to avoid ordering effects.

Round 2: Discussion of uncertain and disagreed links. The aim of Round 2 was to facilitate a discussion of experts' ratings of BCT x MoA links, particularly for the links that elicited high levels of disagreement and/or uncertainty among each of the five groups of experts in Round 1. Round 2 involved an online, anonymous, asynchronous (i.e. experts could contribute at a time of their choosing) discussion hosted via the digital discussion platform Loomio (26). Experts were prompted to discuss (i) the 10 links that were rated 
'Don't Know/Uncertain' by the highest number of experts within their group of experts, and (ii) the 10 for which there were nearly equivalent proportions of experts rating 'Definitely No' and 'Definitely Yes'. Prompts about these 'uncertain’ and ‘disagreed’ links were included to maximise the usefulness of this round in moving the experts towards consensus; however, they were also given the opportunity to discuss other links, and to explore their views on the task more generally.

During the Round 2 discussion, each expert was assigned an identification code to use as a pseudonym throughout the discussion to ensure anonymity. To facilitate participation across time zones, experts were not required to participate in live discussions; instead, they were given a two-week period to comment on discussion threads within their group. Anonymous discussion moderators from the research team addressed questions raised by experts, and prompted discussion periodically during the two-week period by summarising key points from the discussion and by conducting informal polls of experts' opinions during the discussions. Round 2 took place one week after experts received the statistical summaries from Round 1.

Round 3: Final ratings of all BCT x MoA links. The aim of Round 3 was to establish a final understanding of experts' views on the BCT x MoA links. Following the discussion round, experts were invited to rate links between the BCTs and MoAs that they had rated in Round 1 . In response to feedback from experts during the discussion round, the wording and response options were slightly modified from that used in Round 1 (see Round 1 description for the original question and scale). For the final round, experts rated links by answering the question, 'When [BCT] works, does it work through changing [MoA definition (MoA label)]? Experts responded with, 'Definitely Yes', 'Definitely No’, 'Uncertain’, or 'Possibly’.

\section{Materials.}


Round 1. Prior to the start of the first round, experts were emailed their set of 13-14 BCTs, the 26 MoAs including definitions of both, and guidelines for the task (See Appendix E). During Round 1, for each question, experts were provided with the BCT definition, the MoA definition, and a diagram depicting that a BCT influences a MoA, which in turn influences behaviour change

Round 2. After completing Round 1, each expert received an email with a personalised statistical summary of the results of Round 1. This included frequency distributions of their group’s responses, which were depicted alongside their own responses for each BCT x MoA link (see Appendix F). To summarise Round 1 data in an accessible format, the response options were collapsed into 'Yes’ (Definitely and Probably Yes), 'No' (Definitely and Probably No), and ‘Uncertain’ (Don’t Know/Uncertain).

Round 3. During Round 3, experts had access to both their personalised statistical summaries from the Round 1 ratings, and were provided transcripts of their group's Round 2 discussion. The detailed information from the previous rounds allowed experts to re-evaluate their original ratings for each link, in light of the thoughts and ratings of the other experts in their group.

Procedures to evaluate effects of group membership. To detect any effect of group membership (i.e., whether certain groups of experts were more likely to rate BCT x MoA links in a particular way), two of the 13 or 14 BCTs rated by each expert group were rated by all of the experts in Round 1 (i.e., 52 shared BCT x MoA links were rated across the five groups). The BCTs rated by all experts were the two BCTs most frequently identified in our dataset of studies evaluating BCT v1 Taxonomy (8): 'Instruction on How to Perform Behaviour', and 'Social Support (Unspecified)'.

To facilitate comparison of the discussions across groups, two links were discussed in Round 2 by all five expert groups, by selecting the two BCT x MoA links, out of a total of 52 
shared BCT x MoA links, for which there was the most disagreement, (BCT: Instruction on how to perform the behaviour $\rightarrow$ MoA: Intention), and the most uncertainty (BCT: Social Support (Unspecified) $\rightarrow$ MoA: Attitude towards the Behaviour) across all five groups.

\section{Data Analysis}

To address the research questions, through which MoAs do experts agree that BCTs influence behaviour (Question 1), and through which MoAs do experts agree that BCTs do not influence behaviour (Question 2) we conducted descriptive analyses (in MS Excel) on the final ratings from Round 3. This enabled us to describe where there was consensus on links between the 61 BCTs and 26 MoAs. Expert consensus was defined as more than $80 \%$ of experts in agreement that a BCT was either definitely linked or definitely not linked to a MoA. To examine the specificity with which BCTs influence behaviour, we evaluated the BCT x MoA links identified to be definitely linked, to determine whether BCTs were linked to one or more MoAs (Question 3), this information was further analysed to determine whether all BCTs could be linked to one or multiple MoAs (Question 4), and whether all MoAs could be linked to one or multiple BCTs (Question 5). The distribution of the proportion of experts rating 'definitely yes', ‘definitely no', 'possibly,' and 'don’t know/uncertain’ was assessed to report results of disagreement and uncertainty about BCT x MoA links (Question 4).

The final (Round 3) ratings were represented visually in four heat maps generated in $R$ (30). A heat map is a visual representation of a data matrix - in this instance the matrix of BCTs (rows) linked to MoAs (columns) — where the values in the cells are represented by colours, and shaded to indicate the strength or 'heat' of that value. In this case, the values in the cells represent the percentage of experts who agree that a BCT and MoA are 'definitely' linked. The darker the shading in the cells of the heat map, the larger the proportion of experts who rated the link as 'definitely yes' linked, or 'definitely no' not linked. The darkest 
shading in the cells represents $95-100 \%$ of experts agreed on the link. The heat map clusters rows (BCTs) and columns (MoAs) by similarity, such that BCTs linked to similar MoAs are clustered together vertically, and MoAs linked to similar numbers of BCTs are clustered together horizontally. This clustering facilitates visual identification of patterns present within the data, but not statistical inference.

To examine any possible influences of group membership on ratings, intra-class correlation coefficients were calculated for experts’ ratings on the 2 BCTs x 26 MoAs considered by all experts (i.e., 52 links). These intra-class correlation coefficients were calculated for ratings in Round 1 (to examine influences of group allocation) and Round 3 (to examine changes following the group discussion round). The extent to which variance in the ratings can be attributed to group membership can be understood by translating the intra-class correlation coefficient value into a percentage, e.g. if the intra-class correlation is .01, this means $1 \%$ of the variance in the ratings can be attributed to group membership properties. In the absence of standard criteria for intra-class correlation values and group ratings, the results describe rather than evaluate the influence of group membership on the consensus within the group. The Round 1 intra-class correlation coefficients were predicted to be small, because experts were randomly assigned to groups, and stratified to represent different countries, professional backgrounds, and academic disciplines. Round 3 intra-class correlation coefficients were predicted to be larger due to the likely influence of group-specific discussion about the links.

\section{Results}

\section{Round 1}

All experts $(\mathrm{n}=105)$ participated in Round 1. After Round 1, at least $80 \%$ of experts agreed that 13 BCT x MoA links (0.81\%) were 'definite' links, and 3 were 'definitely not' links (0.19\%). At least 50\% of experts agreed that 83 BCT x MoA links (5\%) were 'definite' 
links, 147 (9\%) were 'possibly’ links, 53 (3\%) were 'possibly’ not links, and 296 (19\%) were 'definitely' not links. There were no links for which more than $50 \%$ of experts were uncertain about the BCT x MoA link.

\section{Round 2}

During Round 2, experts in five groups collectively discussed 102 links: the 10 links rated 'Don't Know/Uncertain' by the largest percentage of experts in their group, the 10 for which a nearly equal percentage of experts rated 'Definitely No' and 'Definitely Yes', and two links which were discussed by all five groups, which were the most uncertain and disagreed links across all experts. Ninety-two of the 105 experts actively participated in the discussion round, with the number of comments per expert ranging from 1 to 40 ( $M=13.96$, $S D=7.103)$. The number of experts who did not participate within their discussion group ranged from 0 to 4 experts per group and the total number of comments within a discussion group ranged from 213 to 353 comments. There were no significant differences in the mean number of comments per expert across groups, $F(4,95)=1.684, p=0.161$. The frequency with which the experts participated in the discussion round suggests that experts were engaged in the task, and the comments from experts during the round indicate that experts found the task helpful in reaching consensus. For example, comments included:

"I put uncertain, as I too could not see how [Instruction on how to Perform the Behavior] would necessarily facilitate Intention to act as [Expert] points out... I think the example about smoking from [another Expert] illustrates when this would not apply very effectively. I would change my rating to 'no' now”;

"I have found this one of the most challenging to call and therefore waited to see the arguments of others as I was unable to decide a camp. I too do not feel that intention is the primary MoA [for BCT social comparison], but I see the argument put forward by [Expert]. [...] However my hunch is still that this is not a key MoA therefore I will rate it as 'no'." 
The pattern of ratings and feedback from experts indicated that experts had difficulty with the initial rating task, and in particular found it difficult to discern between 'Possibly Yes' and 'Possibly No'. Experts stated that if they could not judge a link as either definitely linked or not linked, it was difficult to discern which direction to judge the 'possibility' of the link, and requested one 'possibly’ option instead of two. For example, one expert noted, “The two ['probably'] options created a lot of grey area, which experts interpreted differently." Experts also noted having difficulty linking BCTs in general with specific MoAs. For example, experts in two different groups commented on their difficulty rating links with intentions. One expert mentioned, "In general, I struggled with INTENTION as a key MoA for most BCTs. I see Intention as so proximal to behaviour (and analogous to overall motivation) that it is almost always a result of other (more critical) MoAs, no matter which theoretical perspective one adopts," and an expert in a different group made a similar comment, "While I believe 'intention' is not a key MoA in this case, and am thus happy to keep my no vote, I also struggled with 'intention' as MoA in general - I thought it would be involved but not necessarily key to achieving change for almost all BCTs." Some experts also noted that it was challenging to make singular links between BCTs and specific MoAs, "It is very difficult to think about the individual BCTs in isolation. My brain is forced to think about models of behaviour change, directions of causality and other BCTs before making a decision "yes', 'no' or 'unsure'. Although I might say 'yes' to a specific BCT, it's likely that what I'm really saying is that the BCT in question is part of a cluster, but probably plays the biggest part in that cluster.”

\section{Round 3}

Nearly all experts ( $n=100,95 \%)$ participated in the final ratings round. Of the 1,586 possible links (61 BCTs $\times 26$ MoAs), consensus was reached for 90 BCT x MoA links as ‘definite’ links (Question 1) and 464 as ‘definitely not’ links (Question 2; see Appendix G). 
Of the 102 links for which there had been high disagreement and/or uncertainty and were discussed in Round 2, expert consensus emerged for 8 links in Round 3.

Of the 61 BCTs, 51 were rated by experts as definitely linked to at least one MoA. Of the 26 MoAs, 21 were definitely linked to at least one BCT (Questions 5 and 6). Figure 2 depicts the specificity with which BCTs link to MoAs, with frequencies included for the number of BCTs with one or more 'definitely' linked MoAs, and the number of MoAs with one or more ‘definitely’ linked BCTs. Twenty-three BCTs were linked to only one MoA, and 20 BCTs were linked to only two MoAs (Question 3). MoAs were linked to 1-9 BCTs, with the MoA Motivation linked to nine different BCTs. The 10 BCTs with no definite links to MoAs were: Action Planning, Monitoring of Behaviour by Others without Feedback, Monitoring of Outcomes of Behaviour without Feedback, Behavioural Substitution, Generalisation of the Target Behaviour, Credible Source, Non-Specific Incentive, Pharmacological Support, Body Changes, and Self-Talk. The five MoAs with no definite links to BCTs were: General Attitudes and Beliefs, Needs, Optimism, Social Professional Role and Identity, and Values.

\section{[INSERT FIGURE 2]}

Two heat maps (Figures 3-4) present expert responses (i.e. Definitely Yes, or Definitely No) to the question, 'When BCT X works, it does so by changing MoA Y'. All of the values in the heat map, which represent the proportion of experts who agreed on a link as either 'definitely yes’ linked, or 'definitely no’ not linked, can also be viewed in table format in Appendix G. The utility of the heat map is that patterns can be identified visually across a very large data set, such that BCTs which experts agreed were linked to similar MoAs are positioned closer together in the heat map, and MoAs which are linked to a similar frequency of BCTs are closer together. 
There were 1032 (65\%) BCT x MoA links which did not meet the consensus criterion. For 163 links, this was due to strong disagreement among the experts (i.e. one-third of experts said 'Definitely Yes', one-third said 'Definitely No', and one-third said either 'Possibly’ or 'Don’t Know/Uncertain; Question 4). For an additional set of 340 links there was generally agreement among the experts, but not enough to meet the pre-specified consensus criterion. Specifically, 50-80\% of experts rated 255 and 85 links as 'Definitely' not links and definitely links (respectively), with the remaining experts providing ratings of ‘possibly’ and 'Don’t know/Uncertain’. For the remaining 529 links, no meaningful trends emerged among the response options selected by experts.

\section{[INSERT FIGURES 3-4]}

\section{Analysis of Between-Group Differences in Rating Patterns (Intra-Class Correlation \\ Coefficients)}

To assess whether there were group differences in expert ratings we examined intraclass correlation coefficients for the two BCTs shared across groups (i.e., Instruction about how to perform the behaviour; Social Support (Unspecified)). In Round 1, the intra-class correlation coefficients were small for all BCT x MoA links ( $\mid$ range $\mid=0.00-0.10)$, suggesting that allocation to groups did not affect ratings (see Table 2). As anticipated, intra-class correlation coefficients increased from Round 1 to Round 3 for 37 BCT x MoA links, reflecting an increase in agreement within the groups after the discussion in Round 2. In Round 3, 1 out of 52 (1.9\%) intra-class correlation coefficients was large (for the MoA 'General attitudes and Beliefs’ with the BCT 'Social support (unspecified)'), and 13 of 52 (25\%) were moderately-sized. Ten of those were for the BCT 'Social support (unspecified)', it thus seems that the Round 2 discussions led to higher agreement on the meaning of this BCT in some groups than in others. 


\section{Discussion}

The aim of the current study was to identify links between 61 commonly used BCTs, and 26 frequently occurring mechanisms of action. The experts reached consensus for 51 out of 61 BCTs and 20 out of 26 MoAs. Twenty-three of these 51 BCTs were linked to one MoA, and 20 BCTs to two or more MoAs, with a total of 90 identified links. Experts also agreed that 464 out of a total of 1,586 possible links definitely did not exist - agreeing these should not be targeted in interventions. Experts did not reach agreement on the remaining 1,032 BCT x MoA links, suggesting disagreement on the majority of BCT x MoA links. No links were identified (either way) for 10 frequently used BCTs and 6 MoAs. Taken together, this study has identified 51 potentially effective BCTs for modifying 20 frequently-used MoAs to inform intervention development and evidence synthesis. Additionally, this study identified which BCT x MoA links are likely to not exist, and revealed that on the majority of links experts could not achieve $80 \%$ agreement. These links could be of particular interest for future research.

Based on the pattern of BCT x MoA links which were either definitely agreed upon, or which showed a trend towards agreement but failed to reach consensus, experts agreed that most of the BCTs assessed in this task change behaviour through changes in motivation, and intention. There were also a large number of BCTs that were hypothesized to operate through the MoAs: beliefs about capabilities, beliefs about consequences, and behavioural regulation. BCTs linked to reinforcement, cueing, and environmental context and resources were agreed by nearly all experts rating the links. One possible explanation for the strength of the evidence for these links could be the extent to which the theoretical literature explicitly describes techniques for changing these MoAs. Similarly, the BCT v1 Taxonomy is structured hierarchically to group together BCTs which are more similar in function (7), and several of these groupings appear within the heat map (in terms of vertical proximity) as a 
result of the consensus among the experts as to how individual BCTs link to individual MoAs, which could indicate shared theoretical hypotheses across different consensus studies. For some of the most frequently used BCTs (e.g. Action Planning, Credible Source, Behavioural Substitution (26)), there was no consensus regarding the MoAs they target. Given the engagement of experts with the task, and the increase in agreement across rounds, it is possible additional consensus rounds, more participants per group, and/or an additional consensus exercise with different experts could increase the number of agreed BCT x MoA links. However, the lack of agreed links may be because these BCTs are linked to different MoAs in several different theories, and possibly only work in combination with other BCTs making it difficult to judge these links in isolation. Further, there are several MoAs which occur frequently within theories of behaviour change (e.g. Needs, Values, Optimism), but for which experts could not come to consensus regarding the BCTs that are able to elicit change in them. One possibility is these MoAs need to be targeted by a variety, or a group of BCTs, as noted by experts during the discussion round.

A BCT-MoA-behaviour change effect depends on both the effect of the BCT on the MoA, and the effect of the MoA on behaviour change. Expert ratings may have been influenced by beliefs about both of these effects. For example, non-links could emerge even if the experts had confidence in the BCT's ability to alter the MoA, but had limited confidence in the link between the MoA and behaviour change. This concern was raised by experts during the discussion round. The present study cannot determine whether non-links were a result of experts' confidence in the ability to alter the MoA, or the influence of the MoA on behaviour change. However, the comments by experts prompted the modification of the question wording in Round 3, such that experts considered their judgments in light of the hypothetical, "When this BCT works...” Further research is needed to explore on what basis experts are making their judgments. For example, 95\% of experts agree that 'Goal Setting 
(behaviour)' changes behaviour by eliciting changes in intentions; yet, experts commented (in Round 2) on their difficulty linking any BCTs to intention. This may be due to research suggesting that changes in intentions lead to small to medium-sized changes in behaviour (31-34).

We chose a stringent consensus criterion of $80 \%$ agreement among experts in this study. In a systematic review of previous expert consensus studies, the most commonly used method for assessing consensus is percentage of experts in agreement, and the median threshold value used was 75\%, with a range of 50-97\% (35). We chose a stringent criterion because of the relatively small number of experts rating each link compared to the number of links rated by each expert. However, the links for which more than two-thirds of experts agreed (i.e. the more moderately shaded links in the heat map) may also be considered for hypothesis testing.

At present, intervention developers tend to consult theory, empirical literature, and common sense to decide which BCTs to utilise for modifying the MoA deemed relevant for changing the behaviour of interest. Hence, these links are based on the interpretation of the literature by that individual (or research team), which - as this study suggests - may be quite different from how other researchers interpret the literature. The current data provide evidence about the shared judgements of experts, and is a resource that can be drawn upon for intervention development and generate data-driven hypotheses. The heat maps, and list of agreed links and non-links, can be used to select BCTs to target relevant MoAs to change behaviour. Similarly, these data can be used to determine which MoAs should be measured to evaluate the process of change within an intervention, and/or to inform intervention evaluation. Of additional interest to intervention designers and evaluators are the data indicating which BCTs are not linked to specific MoAs, and which MoAs are not linked to specific BCTs. 
Further, these results generate hypotheses about effective links and provide the basis for a programme of empirical research to test the most promising BCT-MoA links. The varying levels of agreement among 100 experts, for approximately 1000 BCT x MoA links, provides an important foundation for future empirical testing, and to increase our understanding of how intervention components have their effects.

\section{Limitations}

The range of links identified in this study was restricted to those we evaluated, which represented only a sub-set of possible links (i.e. 61 of 93 BCTs in the BCT v1 Taxonomy). Secondly, we chose specific inclusion/exclusion criteria for selecting experts, and it is possible a different recruitment strategy might have led to different results; however, the large number of experts included in the study, the screening tools used to balance the pool of experts, and the variety of recruitment procedures used were intended to mitigate bias in the findings due to the expert pool. There was some evidence that certain expert groups were able to agree more upon certain BCT x MoA links than other groups, based on the between-group analyses. Most of the links with better agreement among some expert groups than others, were for the BCT 'Social support (unspecified)', which in previous studies has lower-thanaverage reliability $(7,36)$. The question prompt and rating scale for evaluating BCT x MoA links changed from Round 1 to Round 3, which could have limited the consensus among experts. The use of the original rating scale may have reduced the total number of links agreed upon at the end of the exercise due to the difficulty experts reported after Round 1. Lastly, BCTs were rated on the extent to which they change behaviour through a finite set of MoAs. These MoAs were selected because of their frequency in behaviour change theories; there may be other important MoAs to consider which were not captured.

\section{Future Directions}


Although the current research addresses theoretically-based MoAs, these MoAs have not been linked to theories or theoretical frameworks directly. Theories propose how MoAs interact to have an effect on behaviour and therefore how and why the effects of BCTs might occur. There is clearly scope to explore whether the BCT x MoA links have additive (independent), synergistic, or antagonistic effects, as has been investigated in previous research (37-39).

To improve theory development, other work in the current programme of research (Michie et al., 2016) is assessing whether the agreed links between BCTs and MoAs are consistent with the BCT-MoA links that are specified in behaviour change theories. For more information about the progress of this work, and to access the latest evidence on BCT x MoA links, as well as a link to view a high resolution, colour version of the heat maps, see https://theoryandtechniquetool.humanbehaviourchange.org/. The next stage in this programme is to examine how the links found in this study relate to a previous study (see Carey et al., under review), examining links found in the published behaviour change intervention literature and to investigate differences in the links found in the two studies.

\section{Conclusions}

The findings from this study represent a systematically drawn consensus of experts’ judgments about the mechanisms through which BCTs do or do not change behaviour. The definite links between BCTs and MoAs identified in this study - 90 present and 464 not present - can be used to inform intervention development and synthesis. The considerable uncertainty about the majority of BCT-MoA links could be of particular interest for future studies. These results can be considered as a first level of evidence, generating hypotheses which can be confirmed or refuted through further empirical studies to understand the mechanisms by which BCTs have their effects in changing behaviour. 


\section{Acknowledgements}

We would like to express our gratitude to all of the experts in behaviour change theory and interventions who participated in this study, and to all the researchers, particularly Hilary Groarke who assisted in the preparation of figures. Support for the preparation of this manuscript was also supported by T32 HL076134 (Connell)

\section{Statement of Competing Interests}

Authors Rachel N. Carey, Lauren Connell, Marie Johnston, Alexander J. Rothman, Marijn de Bruin and Michael P. Kelly have no conflicts of interest. Susan Michie is Director of the Centre for Behaviour Change, UCL which has received funds from industry and government agencies. 


\section{References}

1. Kontis V, Mathers CD, Rehm J, et al.: Contribution of six risk factors to achieving the $25 \times 25$ non-communicable disease mortality reduction target: a modelling study. The Lancet. 2014, 384:427-437.

2. Lim SS, Vos T, Flaxman AD, et al.: A comparative risk assessment of burden of disease and injury attributable to 67 risk factors and risk factor clusters in 21 regions, 1990-2010: a systematic analysis for the Global Burden of Disease Study 2010. The Lancet. 2013, 380:22242260.

3. de Bruin M, Oberjé EJ, Viechtbauer W, et al.: Effectiveness and cost-effectiveness of a nursedelivered intervention to improve adherence to treatment for HIV: a pragmatic, multicentre, open-label, randomised clinical trial. The Lancet Infectious Diseases. 2017, 17:595-604.

4. Marteau T, Hollands G, Kelly M, et al.: Changing population behavior and reducing health disparities: Exploring the potential of “choice architecture” interventions. Emerging Behavioral and Social Science Perspectives on Population Health. Rockville: Agency for Healthcare Research and Quality and Office of Behavioral and Social Sciences Research: AHRQ Publication. 2015.

5. NICE: Behaviour change: Individual approaches (PH4).

6. Hoffmann TC, Glasziou PP, Boutron I, et al.: Better reporting of interventions: template for intervention description and replication (TIDieR) checklist and guide. Bmj-British Medical Journal. 2014, 348.

7. Michie S, Richardson M, Johnston M, et al.: The Behavior Change Technique Taxonomy (v1) of 93 Hierarchically Clustered Techniques: Building an International Consensus for the Reporting of Behavior Change Interventions. Annals of Behavioral Medicine. 2013, 46:81-95.

8. Michie S, Wood C, Johnston M, et al.: Behaviour Change Techniques: The Devlelopment and Evaluation of a Taxonomic Method for Reporting and Describing Behaviour Change Interventions. Health Technology Assessment. 2015, 19.

9. Kok G, Gottlieb NH, Peters GJY, et al.: A taxonomy of behaviour change methods: an Intervention Mapping approach. Health Psychology Review. 2016, 10:297-312.

10. Michie S, Prestwich A: Are Interventions Theory-Based? Development of a Theory Coding Scheme. Health Psychology. 2010, 29:1-8.

11. Cane J, O'Connor D, Michie S: Validation of the theoretical domains framework for use in behaviour change and implementation research. Implementation Science. 2012, 7:17.

12. Michie S, Johnston M, Abraham C, et al.: Making psychological theory useful for implementing evidence based practice: a consensus approach. Quality \& Safety in Health Care. 2005, 14:26-33.

13. Eldredge LKB, Markham CM, Ruiter RA, Kok G, Parcel GS: Planning health promotion programs: an intervention mapping approach: John Wiley \& Sons, 2016.

14. Gielen AC, McDonald EM, Gary TL, Bone LR: Using the precede-proceed model to apply health behavior theories. Health behavior and health education: Theory, research, and practice. 2008, 4:407-429.

15. Michie S, van Stralen MM, West R: The behaviour change wheel: a new method for characterising and designing behaviour change interventions. Implementation science. 2011, 6:42.

16. Patterson SM, Hughes C, Kerse N, Cardwell CR, Bradley MC: Interventions to improve the appropriate use of polypharmacy for older people. Cochrane Database of Systematic Reviews. 2012:80.

17. Kelly M, Morgan A, Ellis S, et al.: Evidence based public health: A review of the experience of the National Institute of Health and Clinical Excellence (NICE) of developing public health guidance in England. Social Science \& Medicine. 2010, 71:1056-1062.

18. Kelly MP, Moore TA: Methodological, Theoretical, Infrastructural, and Design Issues in Conducting Good Outcome Studies. Research on Social Work Practice. 2011, 21:644-653. 
19. Harkin B, Webb TL, Chang BP, et al.: Does monitoring goal progress promote goal attainment? A meta-analysis of the experimental evidence. American Psychological Association, 2016.

20. Harvey N, Holmes CA: Nominal group technique: An effective method for obtaining group consensus. International Journal of Nursing Practice. 2012, 18:188-194.

21. Vella K, Goldfrad C, Rowan K, Bion J, Black N: Use of consensus development to establish national research priorities in critical care. British Medical Journal. 2000, 320:976-980.

22. Michie S, Carey RN, Johnston M, et al.: From Theory-Inspired to Theory-Based Interventions: A Protocol for Developing and Testing a Methodology for Linking Behaviour Change Techniques to Theoretical Mechanisms of Action. Annals of Behavioral Medicine. 2016:1-12.

23. Van de Ven AH, Delbecq AL: The nominal group as a research instrument for exploratory health studies. American Journal of Public Health. 1972, 62:337-342.

24. Jorm A: Using the Delphi expert consensus method in mental health research. Australian \& New Zealand Journal of Psychiatry. 2015:1-11.

25. Qualtrics: Qualtrics Research Suite. Provo, Utah, USA, 2015, Qualtrics Research Suite.

26. Loomio: Loomio. 2015.

27. Michie S, Wood CE, Johnston M, et al.: Behaviour change techniques: the development and evaluation of a taxonomic method for reporting and describing behaviour change interventions (a suite of five studies involving consensus methods, randomised controlled trials and analysis of qualitative data). Health Technology Assessment. 2015, 19:1-+.

28. Cane J, O'Connor D, Michie S: Validation of the theoretical domains framework for use in behaviour change and implementation research. Implementation Science. 2012, 7:37.

29. Michie S, West R, Campbell R, Brown J, Gainforth H: ABC of Behaviour Change Theories: Silverback Publishing, 2014.

30. Team R: R: a language and environment for statistical computing $R$ Foundation for Statistical Computing, 2.13. Vienna, Austria, 2011: ISBN 3-900051-07-0, URL http://www. R-project. org.

31. Webb TL, Sheeran P: Does changing behavioral intentions engender behavior change? A metaanalysis of the experimental evidence. Psychological Bulletin. 2006, 132:249.

32. Sheeran P, Harris PR, Epton T: Does Heightening Risk Appraisals Change People's Intentions and Behavior? A Meta-Analysis of Experimental Studies. Psychological Bulletin. 2014, 140:511-543.

33. Sheeran P, Maki A, Montanaro E, et al.: The impact of changing attitudes, norms, and selfefficacy on health-related intentions and behavior: A meta-analysis. American Psychological Association, 2016.

34. Rhodes RE, Dickau L: Experimental evidence for the intention-behavior relationship in the physical activity domain: A meta-analysis. American Psychological Association, 2012.

35. Diamond IR, Grant RC, Feldman BM, et al.: Defining consensus: A systematic review recommends methodologic criteria for reporting of Delphi studies. Journal of Clinical Epidemiology. 2014, 67:401-409.

36. Abraham C, Wood CE, Johnston M, et al.: Reliability of identification of behavior change techniques in intervention descriptions. Annals of Behavioral Medicine. 2015, 49:885-900.

37. Michie S, Abraham C, Whittington C, McAteer J, Gupta S: Effective techniques in healthy eating and physical activity interventions: a meta-regression. Health Psychology. 2009, 28:690.

38. Dombrowski SU, Sniehotta FF, Johnston M, et al.: Optimizing acceptability and feasibility of an evidence-based behavioral intervention for obese adults with obesity-related co-morbidities or additional risk factors for co-morbidities: an open-pilot intervention study in secondary care. Patient Educ Couns. 2012, 87:108-119.

39. Ivers N, Jamtvedt G, Flottorp S, et al.: Audit and feedback: effects on professional practice and healthcare outcomes. The Cochrane Library. 2012. 


\section{Tables}

Table 1

List of 26 Mechanisms of Action Rated for Links with Behaviour Change Techniques

\author{
Mechanism Label \\ Knowledge \\ Skills \\ Social/ Professional Role \\ and Identity
}

Beliefs about Capabilities

Optimism

Beliefs about Consequences

\section{Reinforcement}

Intentions

Goals

Memory, Attention and

Decision Processes

Environmental Context and Resources

Social Influences

\section{Mechanism Definition}

An awareness of the existence of something

An ability or proficiency acquired through practice

A coherent set of behaviours and displayed personal qualities of an individual in a social or work setting

Beliefs about one's ability to successfully carry out a behaviour

Confidence that things will happen for the best or that desired goals will be attained

Beliefs about the consequences of a behaviour (i.e. perceptions about what will be achieved and/or lost by undertaking a behaviour, as well as the probability that a behaviour will lead to a specific outcome)

Processes by which the frequency or probability of a response is increased through a dependent relationship or contingency with a stimulus or circumstance

A conscious decision to perform a behaviour or a resolve to act in a certain way

Mental representations of outcomes or end states that an individual wants to achieve

Ability to retain information, focus on aspects of the environment and choose between two or more alternatives

Aspects of a person's situation or environment that discourage or encourage the behaviour

Those interpersonal processes that can cause oneself to change one's thoughts, feelings or behaviours.

A complex reaction pattern involving experiential, behavioural, and physiological elements 


\begin{tabular}{ll}
\hline Behavioural Regulation & $\begin{array}{l}\text { Behavioural, cognitive and/or emotional skills for managing or changing } \\
\text { behaviour }\end{array}$ \\
Norms & $\begin{array}{l}\text { The attitudes held and behaviours exhibited by other people within a social } \\
\text { group }\end{array}$
\end{tabular}

Subjective Norms

\section{Attitude towards the behaviour}

Motivation

Self-image

Needs

Values

Feedback Processes

Social Learning / Imitation

\section{Behavioural Cueing}

General Attitudes/ Beliefs

Perceived susceptibility/ vulnerability
One's perceptions of what most other people within a social group believe and do

The general evaluations of the behaviour on a scale ranging from negative to positive

Processes relating to the impetus that gives purpose or direction to behaviour and operates at a conscious or unconscious level

One's conception and evaluation of oneself, including psychological and physical characteristics, qualities and skills

Deficit of something required for survival, well-being or personal fulfilment

Moral, social or aesthetic principles accepted by an individual or society as a guide to what is good, desirable or important

Processes through which current behaviour is compared against a particular standard

A process by which thoughts, feelings and motivational states observed in others are internalised and replicated without the need for conscious awareness

Processes by which behaviour is triggered from either the external environment, the performance of another behaviour, or from ideas appearing in consciousness

Evaluations of an object, person, group, issue or concept on a scale ranging from negative to positive

Perceptions of the likelihood that one is vulnerable to a threat 
Table 2

Intraclass Correlation Coefficients for the BCT-MoA Links Rated by All Experts

\begin{tabular}{|c|c|c|c|c|c|c|}
\hline \multirow[t]{2}{*}{ Mechanism of Action } & \multicolumn{3}{|c|}{$\begin{array}{l}\text { Social Support } \\
\text { (Unspecified) }\end{array}$} & \multicolumn{3}{|c|}{$\begin{array}{l}\text { Instruction on how to } \\
\text { Perform a Behaviour }\end{array}$} \\
\hline & Round 1 & Round 3 & $\Delta$ & Round 1 & Round 3 & $\Delta$ \\
\hline Knowledge & 0.05 & -0.01 & -0.06 & -0.03 & -0.04 & -0.01 \\
\hline Skills & 0.05 & 0.07 & 0.02 & 0.00 & 0.02 & 0.02 \\
\hline Behavioural Regulation & 0.07 & 0.12 & 0.05 & 0.09 & 0.11 & 0.02 \\
\hline Social Influences & 0.00 & -0.01 & -0.01 & -0.01 & 0.01 & 0.02 \\
\hline $\begin{array}{l}\text { Memory, Attention, Decision } \\
\text { Processes }\end{array}$ & 0.01 & 0.02 & 0.01 & 0.04 & 0.02 & -0.02 \\
\hline $\begin{array}{l}\text { Social Professional Role / } \\
\text { Identity }\end{array}$ & 0.02 & 0.10 & 0.08 & 0.01 & 0.02 & 0.01 \\
\hline Beliefs about Capabilities & 0.09 & 0.18 & 0.09 & 0.02 & 0.01 & -0.01 \\
\hline Beliefs about Consequences & 0.03 & 0.05 & 0.02 & -0.03 & 0.01 & 0.04 \\
\hline Optimism & -0.04 & 0.01 & 0.05 & -0.02 & 0.01 & 0.03 \\
\hline Intention & 0.00 & 0.10 & 0.10 & -0.02 & 0.08 & 0.10 \\
\hline Goals & 0.04 & 0.07 & 0.03 & 0.07 & 0.06 & -0.01 \\
\hline Reinforcement & 0.10 & 0.13 & 0.03 & 0.03 & 0.04 & 0.01 \\
\hline Emotion & 0.03 & 0.08 & 0.05 & 0.00 & 0.03 & 0.03 \\
\hline Environment & 0.01 & 0.01 & 0.00 & 0.03 & 0.00 & -0.03 \\
\hline Norms & -0.01 & -0.02 & -0.01 & 0.00 & 0.01 & 0.01 \\
\hline Subjective Norms & 0.00 & -0.03 & -0.03 & -0.02 & 0.03 & 0.05 \\
\hline Attitude towards the Behaviour & 0.01 & 0.24 & 0.23 & -0.01 & 0.23 & 0.24 \\
\hline Motivation & 0.03 & 0.07 & 0.04 & 0.00 & 0.00 & 0.00 \\
\hline Self-Image & -0.03 & 0.00 & 0.03 & 0.04 & 0.07 & 0.03 \\
\hline Needs & -0.02 & 0.09 & 0.11 & -0.03 & 0.05 & 0.08 \\
\hline Values & -0.02 & 0.17 & 0.19 & 0.00 & 0.06 & 0.06 \\
\hline Feedback Processes & -0.01 & 0.02 & 0.03 & 0.00 & 0.02 & 0.02 \\
\hline General Attitudes and Beliefs & 0.08 & 0.26 & 0.18 & 0.03 & 0.10 & 0.07 \\
\hline Social Learning & 0.04 & 0.21 & 0.17 & 0.07 & 0.05 & -0.02 \\
\hline Cueing & 0.07 & 0.06 & -0.01 & -0.02 & 0.05 & 0.07 \\
\hline $\begin{array}{l}\text { Perceived Susceptibility / } \\
\text { Vulnerability }\end{array}$ & 0.03 & 0.03 & 0.00 & 0.05 & 0.05 & 0.00 \\
\hline
\end{tabular}

Note. $\Delta$ = Change in the intra-class correlation coefficient from Round 1 to Round 3. Social

Support (Unspecified), and Instruction on How to Perform the Behaviour are the Behaviour

Change Techniques (BCTs) rated by all experts for links with the 26 mechanisms of action.

Values in the table indicate the intraclass correlation coefficient for each link rated by all experts who had been randomly allocated to one of five groups. 


\section{Figure Captions}

Figure 1. Descriptive characteristics of experts included in the consensus exercise. Panel A = selfreported work sector; Panel B = geographical location; Panel C = professional background. Axis labels are in descending order, and label the pie chart in a clockwise direction.

Figure 2. The frequency with which Behaviour Change Techniques (BCTs) were definitely linked to Mechanisms of Action (MoAs) by $>80 \%$ of experts is depicted in the dark grey bars, and the frequency with which MoAs were linked to BCTs by $>80 \%$ of experts is depicted in the light grey bars.

Figure 3. A heat map indicating the proportion of experts rating a behaviour change technique (BCT) was 'definitely' linked to a mechanism of action (MoA). Values range from $0-1$, with values closer to 1 shaded in the darkest grey. A 1 indicates $100 \%$ of experts agreed a BCT was definitely linked to a MoA. M.A.D.P. = Memory, Attention, \& Decision Processes; P.S.V. = Perceived Susceptibility \& Vulnerability; S.P.R.I = Social/Professional Role \& Identity; B. Con. = Beliefs about Consequences; G.A.B. $=$ General Attitudes \& Beliefs; A.T.B $=$ Attitude towards the Behaviour; B.R. $=$ Behavioural Regulation; B.Cap. = Beliefs about Capabilities

Figure 4. A heat map indicating the proportion of experts rating a behaviour change technique (BCT) was 'definitely' linked to a mechanism of action (MoA). Values range from 0-1, with values closer to 1 shaded in the darkest grey. A 1 indicates $100 \%$ of experts agreed a BCT was definitely not linked to a MoA. M.A.D.P. = Memory, Attention, \& Decision Processes; P.S.V. = Perceived Susceptibility \& Vulnerability; S.P.R.I = Social/Professional Role \& Identity; B. Con. = Beliefs about Consequences; G.A.B. = General Attitudes \& Beliefs; A.T.B = Attitude towards the Behaviour; B.R. = Behavioural Regulation; B.Cap. = Beliefs about Capabilities. 
A

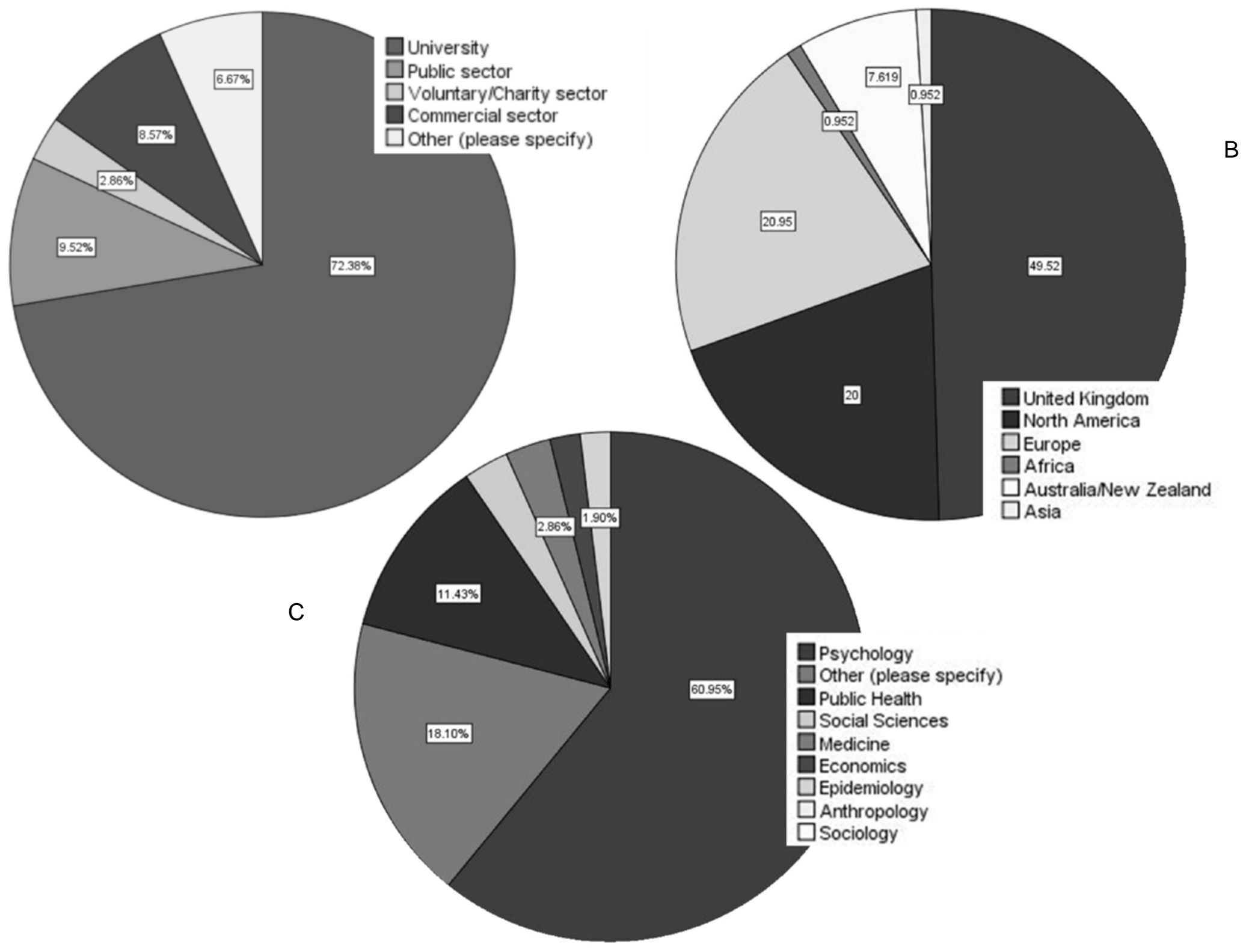




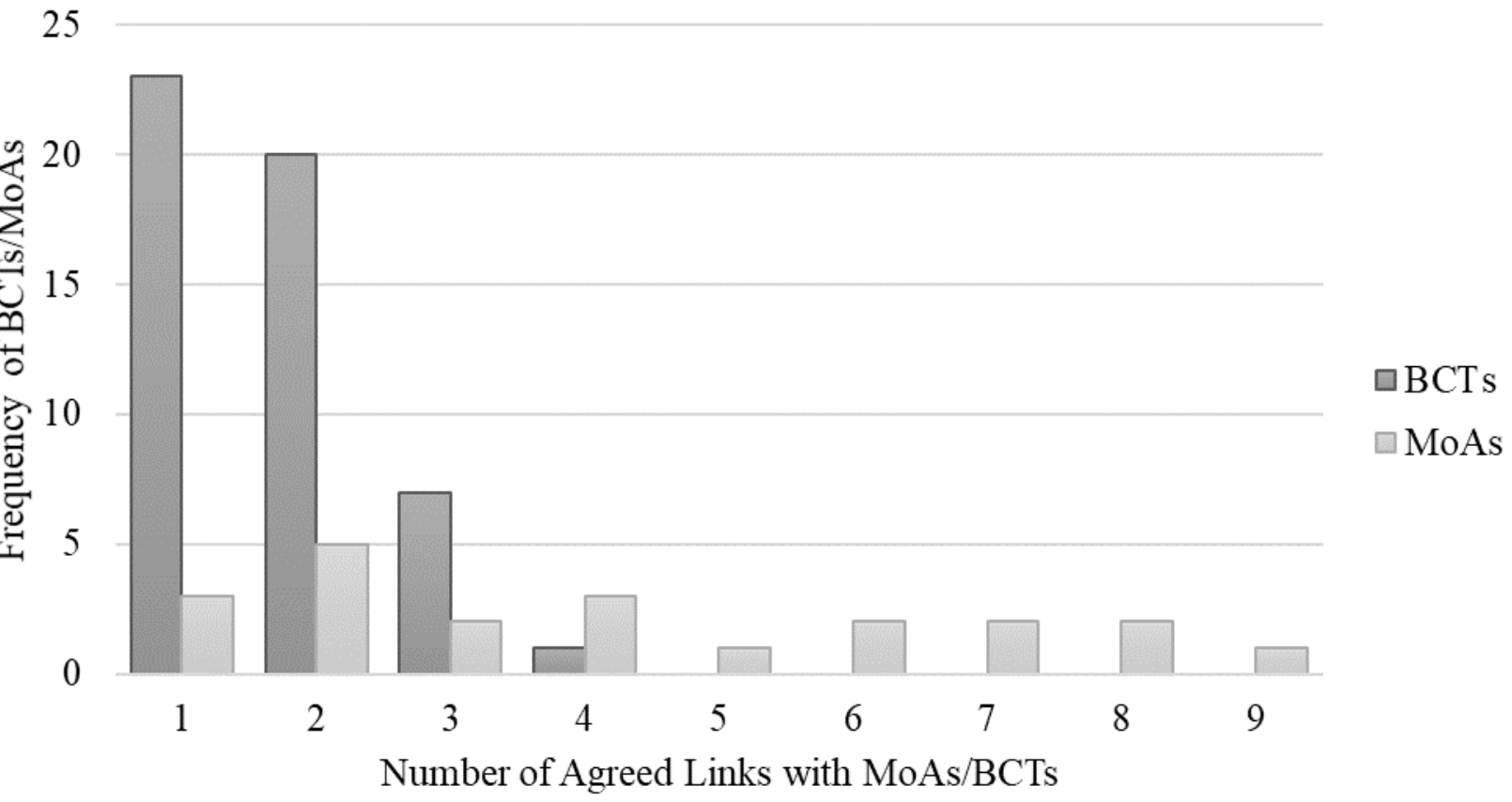

Figure 2 


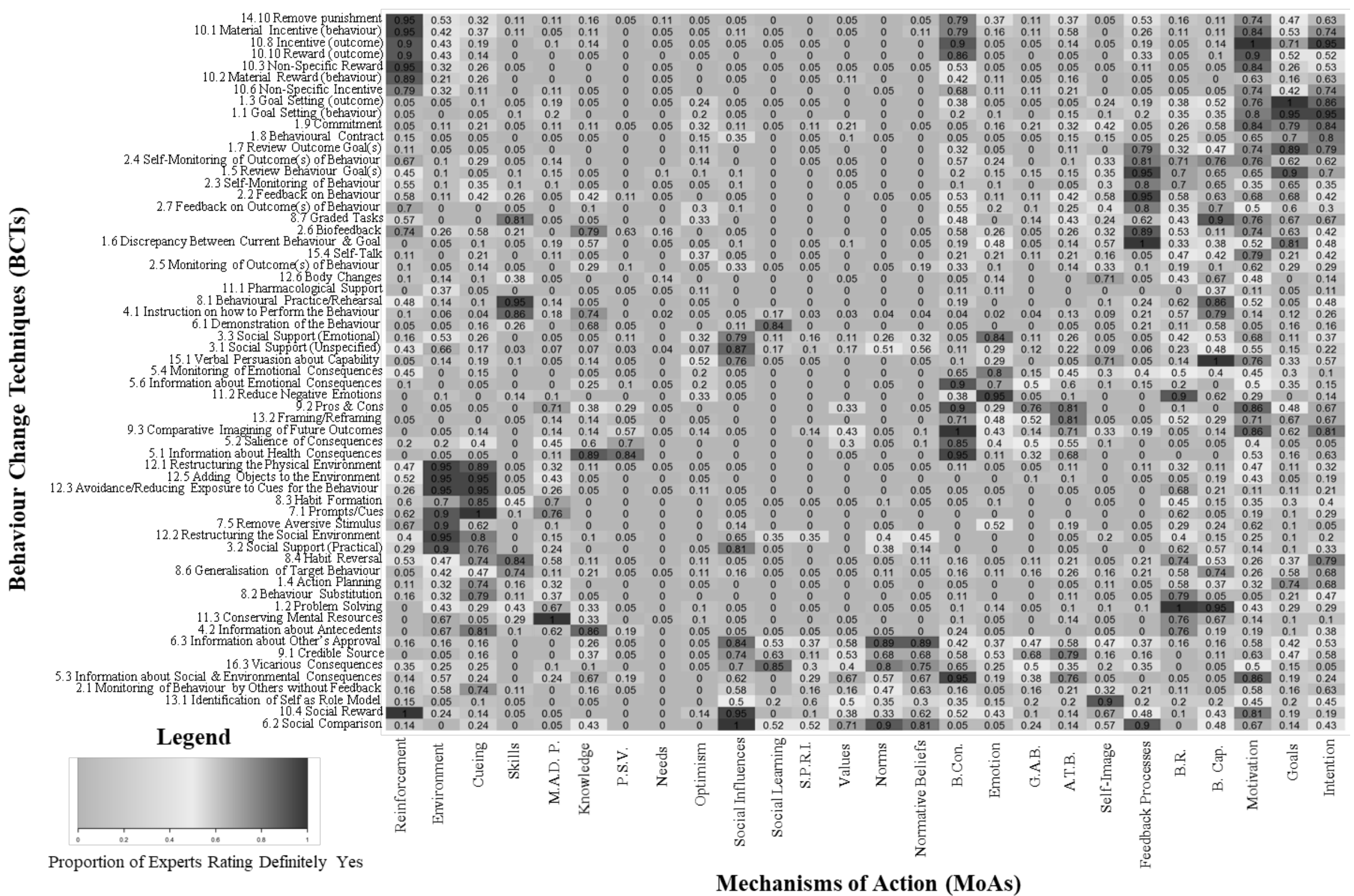

Figure 3 


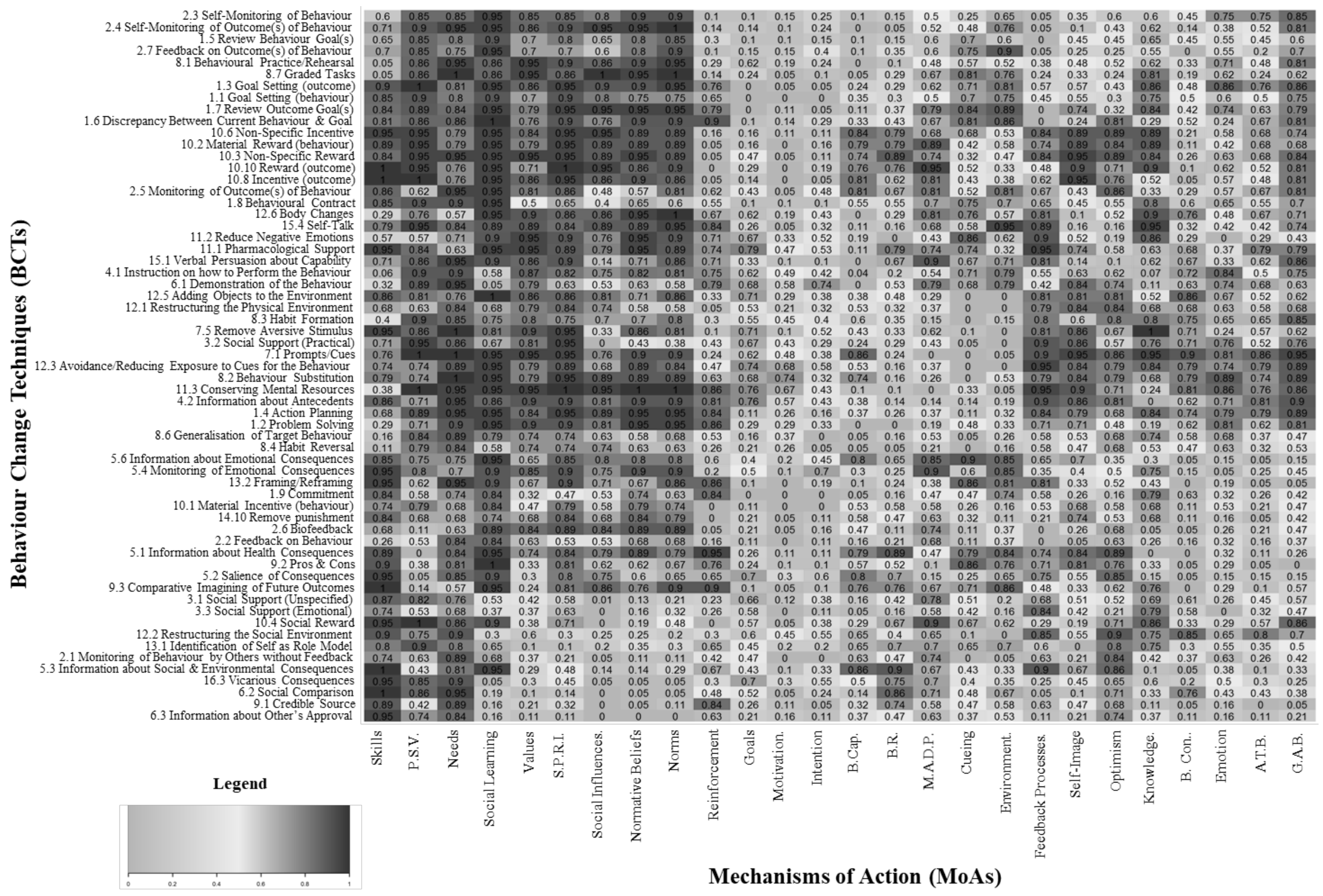

Proportion of Experts Rating Definitely No

Figure 4 


\section{Supplementary Materials}

Appendix A

Study 2 Expert Agreed Explicit Links: Expert Recruitment Self-Evaluation Form

\section{To what extent have you:}

(a) Designed or helped to design a behaviour change intervention(s) that used specific behaviour change techniques (BCTs)?

$\square$ Extensively $\square$ To Some Extent $\square$ Not at all

(b) Used a taxonomy of BCTs (e.g. BCT Taxonomy v1) to code, design, or evaluate a behaviour change intervention?

$\square$ Extensively $\square$ To Some Extent $\square$ Not at all

(c) Designed or helped to design a behaviour change intervention(s) that was specifically grounded in a behaviour change theory/theories?

$\square$ Extensively $\square$ To Some Extent Not at all

(d) Published papers/manuals/protocols of interventions that specify component BCTs? $\square$ Extensively $\square$ To Some Extent $\square$ Not at all

(e) Published papers/manuals/protocols of interventions that specify behaviour change theory/theories?

\section{Extensively $\square$ To Some Extent $\square$ Not at all}

(f) Undertaken a narrative or systematic review of behaviour change literature specifying interventions in terms of BCTs?

$\square$ Extensively $\square$ To Some Extent $\square$ Not at all

(g) Undertaken a narrative or systematic review of behaviour change literature specifying interventions in terms of behaviour change theory?

$\square$ Extensively $\square$ To Some Extent $\square$ Not at all

2. For approximately how many hours have you used BCT methodology? (e.g. 0-5, 10-20, 25-50, 50-100, 100+)

3. For how many studies have you used BCT methodology?

4. For how many studies have you explicitly used behaviour change theory?

5. How would you rate your knowledge/expertise in the following? (where 0 = no knowledge/expertise and 7 = profound knowledge/expertise):

Behaviour change theories $0 \quad 1$ 1 2 3 4 5 6 


\begin{tabular}{|c|c|c|c|c|c|c|c|c|}
\hline Behaviour change techniques & 0 & & 2 & 3 & 4 & 5 & 6 & 7 \\
\hline $\begin{array}{l}\text { Behaviour change interventions } \\
\text { (evaluation or design) }\end{array}$ & 0 & 1 & 2 & 3 & 4 & 5 & 6 & 7 \\
\hline
\end{tabular}

\section{Other relevant experience (please specify):}

7. Please provide your contact details:

\section{Name:}

Email: 
Appendix B

Self-rated Expertise in Designing or Helping Design Behaviour Change Interventions Using Specific Behaviour Change Techniques and/or Theory

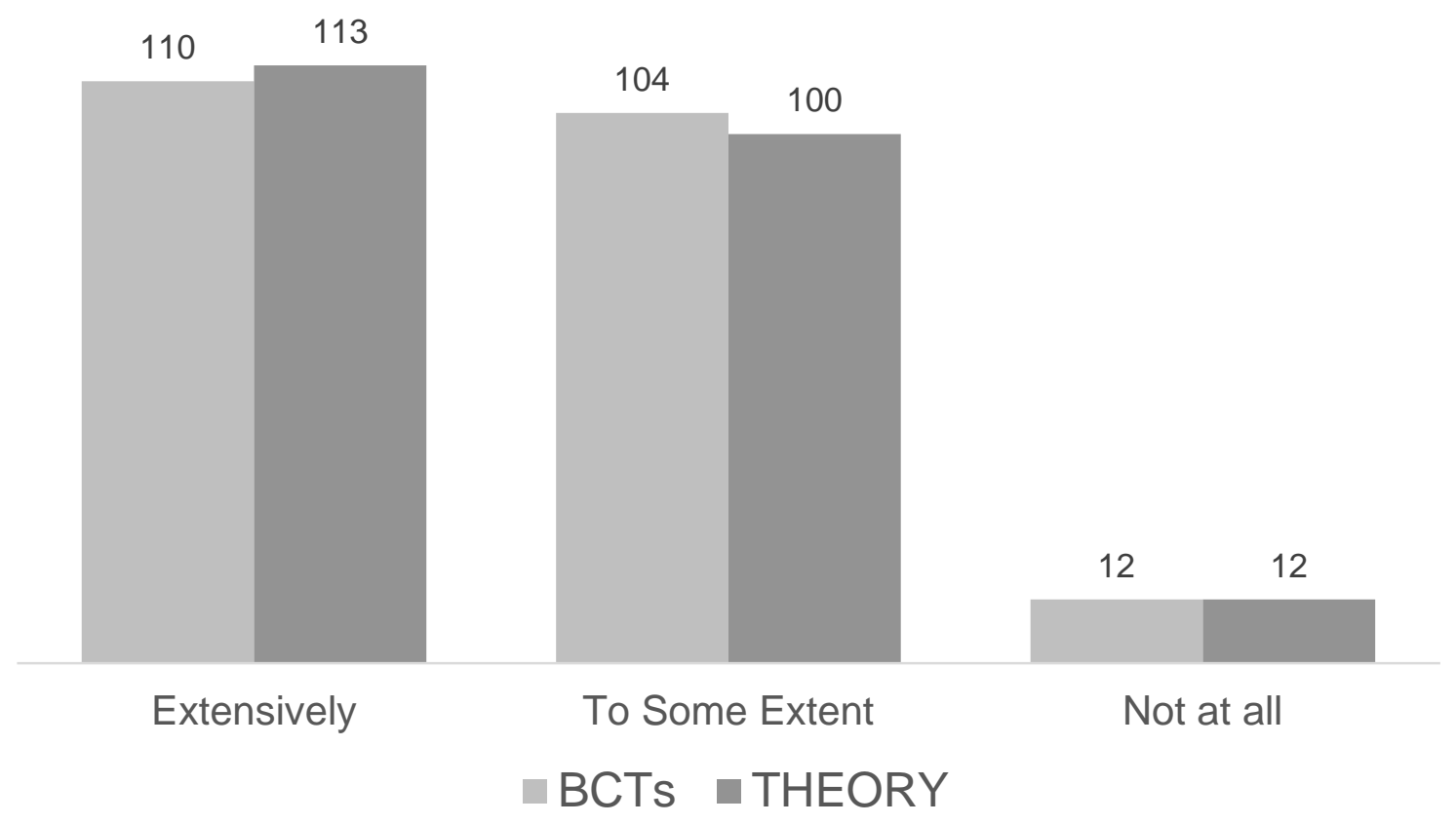

Note. Values indicate the number of experts who rated the extent to which they had designed or helped design a behaviour change intervention using specific behaviour change techniques, or behaviour change theory (See also Appendix A; Questions 1a and 1c). 
Self-rated Expertise in Behaviour Change Theories, Behaviour Change Techniques, and Behaviour Change Interventions

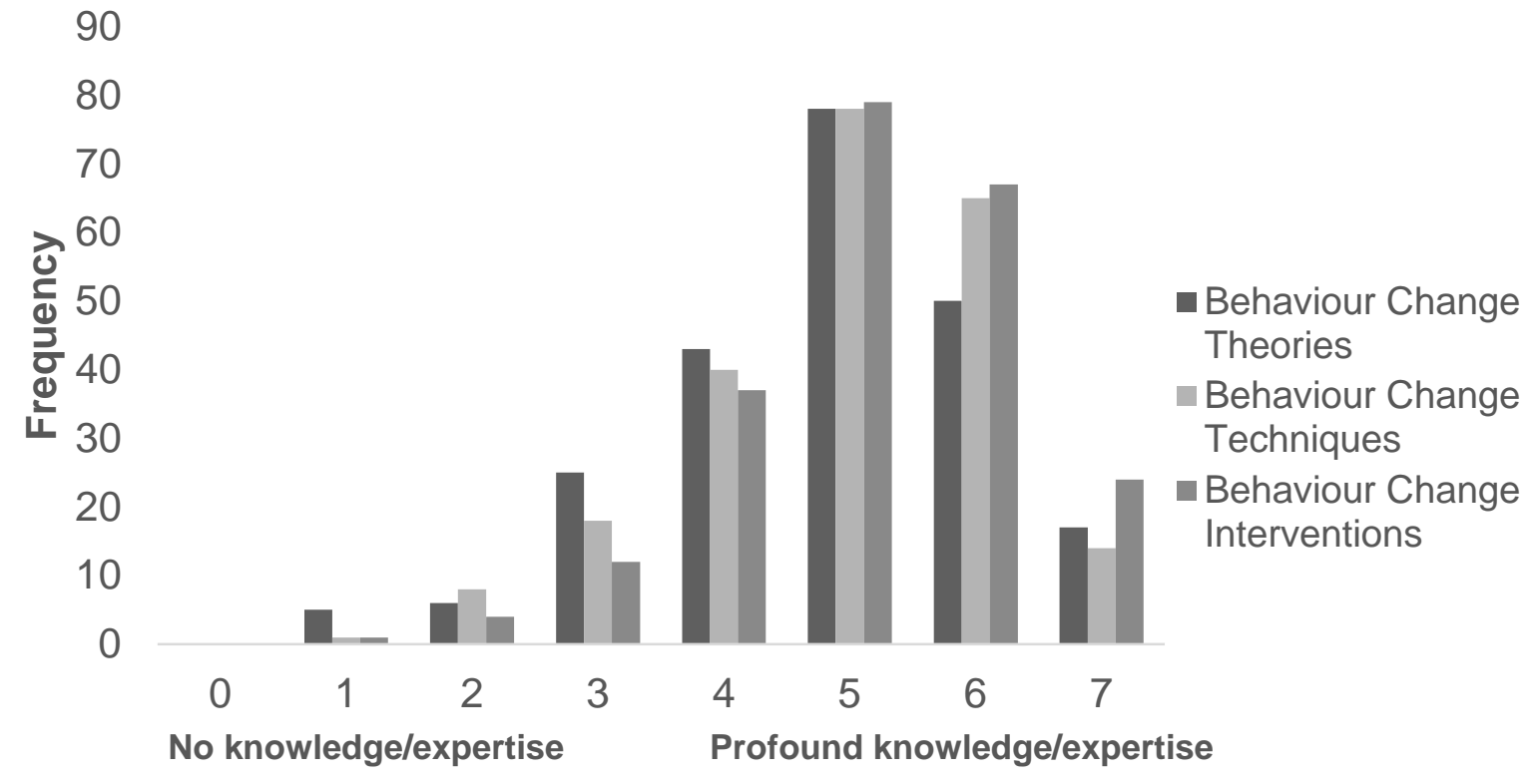

Note. Values indicate the number of experts who rated the extent of their expertise in behaviour change theories, behaviour change techniques, and behaviour change interventions (See Appendix A; Questions 5a-5c). 
Appendix D

Behaviour Change Techniques Rated by Each Expert Group

\begin{tabular}{|c|c|c|c|c|}
\hline Group A & Group B & Group C & Group D & Group E \\
\hline 1.1 Goal Setting (Behaviour) & $\begin{array}{l}5.1 \text { Information about the } \\
\text { health consequences }\end{array}$ & 3.2 Social support (practical) & 9.1 Credible source & $\begin{array}{l}5.3 \text { information about social \& } \\
\text { environmental } \\
\text { consequences }\end{array}$ \\
\hline $\begin{array}{l}\text { 2.7 Feedback on outcome(s) of } \\
\text { behaviour }\end{array}$ & 1.4 Action Planning & $\begin{array}{l}\text { 12.5 Adding objects To The } \\
\text { Environment }\end{array}$ & 2.2 Feedback on behaviour & 1.2 Problem Solving \\
\hline $\begin{array}{l}\text { 2.3 Self-monitoring of } \\
\text { behaviour }\end{array}$ & $\begin{array}{l}\text { 6.1 Demonstration of the } \\
\text { behaviour }\end{array}$ & 7.1 Prompts/cues & $\begin{array}{l}\text { 2.1 Monitoring of behaviour by } \\
\text { others without feedback }\end{array}$ & 1.3 goal setting (outcome) \\
\hline 1.5 Review behaviour goal(s) & 1.6 Review outcome goal(s) & $\begin{array}{l}\text { 8.1 Behavioural } \\
\text { practice/rehearsal }\end{array}$ & $\begin{array}{l}\text { 12.1 Restructuring the physical } \\
\text { environment }\end{array}$ & $\begin{array}{l}\text { Monitoring of outcome of } \\
\text { behaviour without } \\
\text { feedback }\end{array}$ \\
\hline 8.3 Habit Formation & 11.1 Pharmacological support & $\begin{array}{l}\text { 2.4 Self-monitoring of } \\
\text { outcome(s) of behaviour }\end{array}$ & 3.3 Social Support (Emotional) & $\begin{array}{l}\text { 4.2 Information About } \\
\text { Antecedents }\end{array}$ \\
\hline 5.2 Salience of consequences & $\begin{array}{c}\text { 10.2 Material reward } \\
\text { (behaviour) }\end{array}$ & 6.1 Social comparison & 2.6 Biofeedback & $\begin{array}{l}1.6 \text { discrepancy between } \\
\text { current behaviour \& goal }\end{array}$ \\
\hline $\begin{array}{l}\text { 12.2 Restructuring the social } \\
\text { environment }\end{array}$ & 10.3 Non-specific reward & 13.2 Framing/reframing & $\begin{array}{l}\text { 10.1 Material incentive } \\
\text { (behaviour) }\end{array}$ & $\begin{array}{l}15.1 \text { Verbal persuasion about } \\
\text { capability }\end{array}$ \\
\hline 1.8 Behavioural Contract & 10.6 Non-specific incentive & 11.2 reduce negative emotions & 1.9 Commitment & 10.4 Social reward \\
\hline $\begin{array}{l}5.6 \text { Information about } \\
\text { emotional consequences }\end{array}$ & 8.2 Behaviour Substitution & 9.2 Pros \& cons & $\begin{array}{l}\text { 6.3 Information about others' } \\
\text { approval }\end{array}$ & $\begin{array}{l}11.3 \text { Conserving mental } \\
\text { resources }\end{array}$ \\
\hline $\begin{array}{l}\text { 5.4 Monitoring of emotional } \\
\text { consequences }\end{array}$ & 15.4 Self-Talk & 7.5 Remove aversive stimulus & $\begin{array}{l}\text { 8.6 Generalisation of target } \\
\text { behaviour }\end{array}$ & 10.8 Incentive (outcome) \\
\hline $\begin{array}{l}13.1 \text { Identification of self as } \\
\text { role model }\end{array}$ & $\begin{array}{l}\text { 12.3 Avoidance/Reducing } \\
\text { exposure to cues for the } \\
\text { behaviour }\end{array}$ & 8.7 Graded tasks & 8.4 Habit reversal & 10.10 Reward (outcome) \\
\hline 16.3 Vicarious Consequences & & 12.6 Body changes & 14.10 Remove punishment & $\begin{array}{l}\text { 9.3 Comparative imagining of } \\
\text { future outcomes }\end{array}$ \\
\hline
\end{tabular}

Note. All expert groups rated Instruction on How to Perform the Behavior, and Social Support (Unspecified). 


\section{Content of the Guidelines for Round 1 of the Consensus Exercise}

Aims of Study: This study aims to develop a shared understanding of behaviour change techniques (BCTs) and the mechanisms of action through which they influence behaviour. A summary of the project is appended to this document (Appendix A).

Who are the participants? You are one of 105 experts from 18 countries, selected because you have a high level of expertise in theories and techniques of behaviour change.

What are we asking you to do? The consensus exercise is a modified Nominal Group Technique (NGT) (23), involving 3 rounds. In Round 1, you will be directed to an online questionnaire. You will be presented with 13 BCTs, one at a time, and asked to consider whether each BCT changes behaviour through any of a given set of 26 mechanisms of action. Thus, you will be asked to respond to 13 sets of 26 questions, where each set relates to 1 BCT $\times 26$ mechanisms. You will be prompted to take a break after completing each set - you may complete Round 1 in one sitting or several.

What is a Behaviour Change Technique (BCT)? BCTs are the potentially active ingredients of behaviour change interventions. For this study, BCTs will be taken from the 93-item BCT Taxonomy Version 1 (BCTTv1;

http://www.ncbi.nlm.nih.gov/pubmed/23512568)

What is a Mechanism of Action? These are defined as "the processes through which a BCT affects behaviour". The following diagram may be helpful in conceptualising the processes through which a particular BCT might affect behaviour:

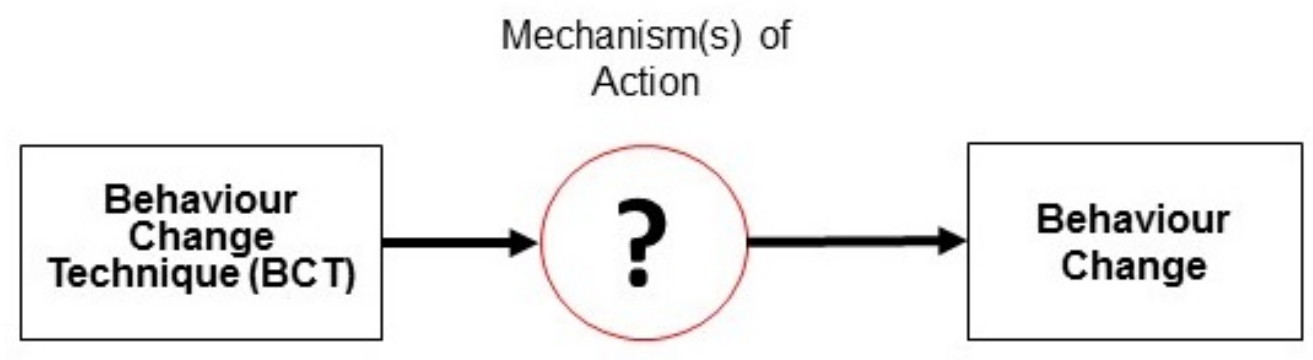

Notes:

1. We are not evaluating the effectiveness of BCTs in this study (i.e. how likely it is that a particular BCT changes behaviour). When rating BCT-mechanism links (see example below), please focus on the mechanisms you believe a BCT might change, in order to change behaviour.

2. There are many mechanisms of action through which a BCT might affect behaviour. When considering whether a given BCT affects behaviour through a particular mechanism, you may draw on evidence, theory and/or experience.

3. In order to ensure consistency across experts, and with the aim of developing a shared understanding of BCT-mechanism links, it is very important that you base your answers on the definitions, rather than labels, of the BCTs and mechanisms. Definitions for all BCTs and mechanisms will appear on screen during the consensus exercise, and these can 
also be found in Appendices B and C. Please read and re-read these definitions before beginning the task.

\section{Sample Question:}

Does the Behaviour Change Technique Goal Setting (Behaviour) change behaviour through the mechanism: An awareness of the existence of something (knowledge)?

$\square$ Definitely No

$\square$ Probably No

$\checkmark$ Uncertain / Don’t Know

Probably Yes

$\square$ Definitely Yes

Note. Additional information provided in the guidelines document was excluded from this paper, this information included a project summary, BCT definitions, and mechanism of action definitions. For more information about the project see the project protocol, published in Annals of Behavioral Medicine, for BCT definitions see the BCT taxonomy app or website: www.bcts.23.co.uk, and for more information about the mechanisms of action included in this study, see the above Table 1. 
Appendix F

Sample Statistical Summary Sent to Experts after the Completion of Round 1

BCT: Goal Setting (Behaviour)

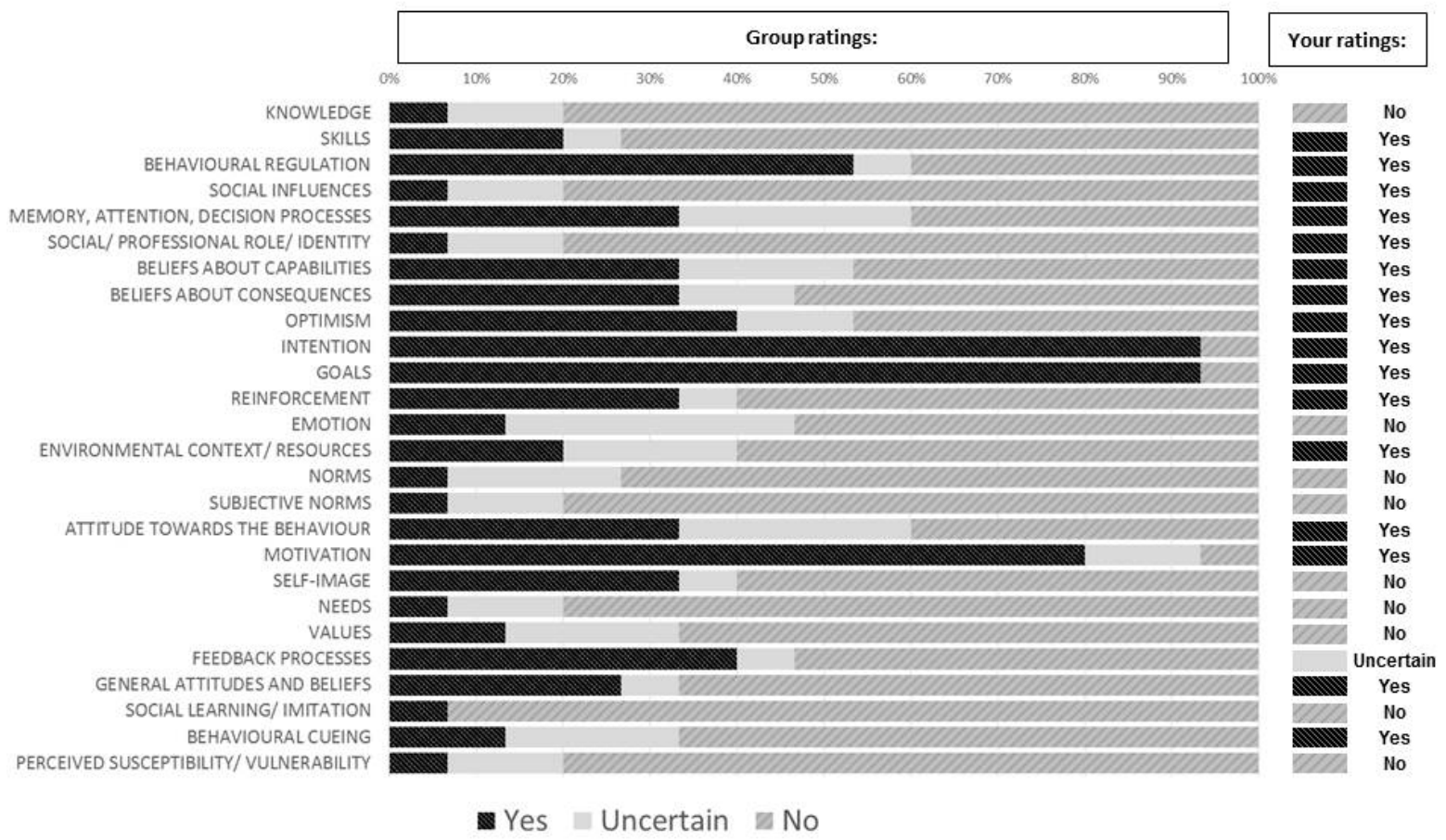

Note. The above distribution depicts the frequency with which experts thought the BCT 'Goal Setting (Behaviour) was linked to any of the 26 mechanisms of action. For Round 1, Yes = Definitely Yes + Probably Yes, No = Definitely No + Probably No. 
Appendix G

\section{Table 1}

Agreed Links between Behaviour Change Techniques and Mechanisms of Action (by Behaviour Change Technique)

\begin{tabular}{|c|c|c|c|c|}
\hline \multirow[b]{2}{*}{ Behaviour Change Technique } & \multicolumn{4}{|c|}{ Mechanism of Action } \\
\hline & 'Definitely Yes' Linked & $\begin{array}{l}\text { Proportion of } \\
\text { Experts }\end{array}$ & 'Definitely No' Not Linked & $\begin{array}{c}\text { Proportion } \\
\text { of Experts }\end{array}$ \\
\hline \multirow[t]{6}{*}{ 1.1 Goal Setting (Behaviour) } & Goals & .95 & Social Learning & 0.90 \\
\hline & Intention & .95 & Social/Professional Role \& Identity & 0.90 \\
\hline & Motivation & .80 & Perceived Susceptibility \& Vulnerability & 0.90 \\
\hline & & & Skills & 0.85 \\
\hline & & & Social Influences & 0.80 \\
\hline & & & Needs & 0.80 \\
\hline \multirow{8}{*}{ 1.2 Problem Solving } & Beliefs about Capabilities & .95 & Norms & 0.95 \\
\hline & & & Social Learning & 0.95 \\
\hline & & & Social/Professional Role \& Identity & 0.90 \\
\hline & & & Values & 0.90 \\
\hline & & & Needs & 0.90 \\
\hline & & & Reinforcement & 0.86 \\
\hline & & & Social Influences & 0.81 \\
\hline & & & General Attitudes \& Beliefs & 0.81 \\
\hline \multirow{12}{*}{ 1.3 Goal Setting (outcome) } & Intention & 0.86 & Social/ Professional Role \& Identity & 0.95 \\
\hline & & & Norms & 0.95 \\
\hline & & & Social Learning / Imitation & 0.95 \\
\hline & & & Skills & 0.90 \\
\hline & & & Social Influences & 0.90 \\
\hline & & & Subjective Norms & 0.90 \\
\hline & & & Knowledge & 0.86 \\
\hline & & & Emotion & 0.86 \\
\hline & & & Values & 0.86 \\
\hline & & & General Attitudes \& Beliefs & 0.86 \\
\hline & & & Environmental Context \& Resources & 0.81 \\
\hline & & & Needs & 0.81 \\
\hline
\end{tabular}




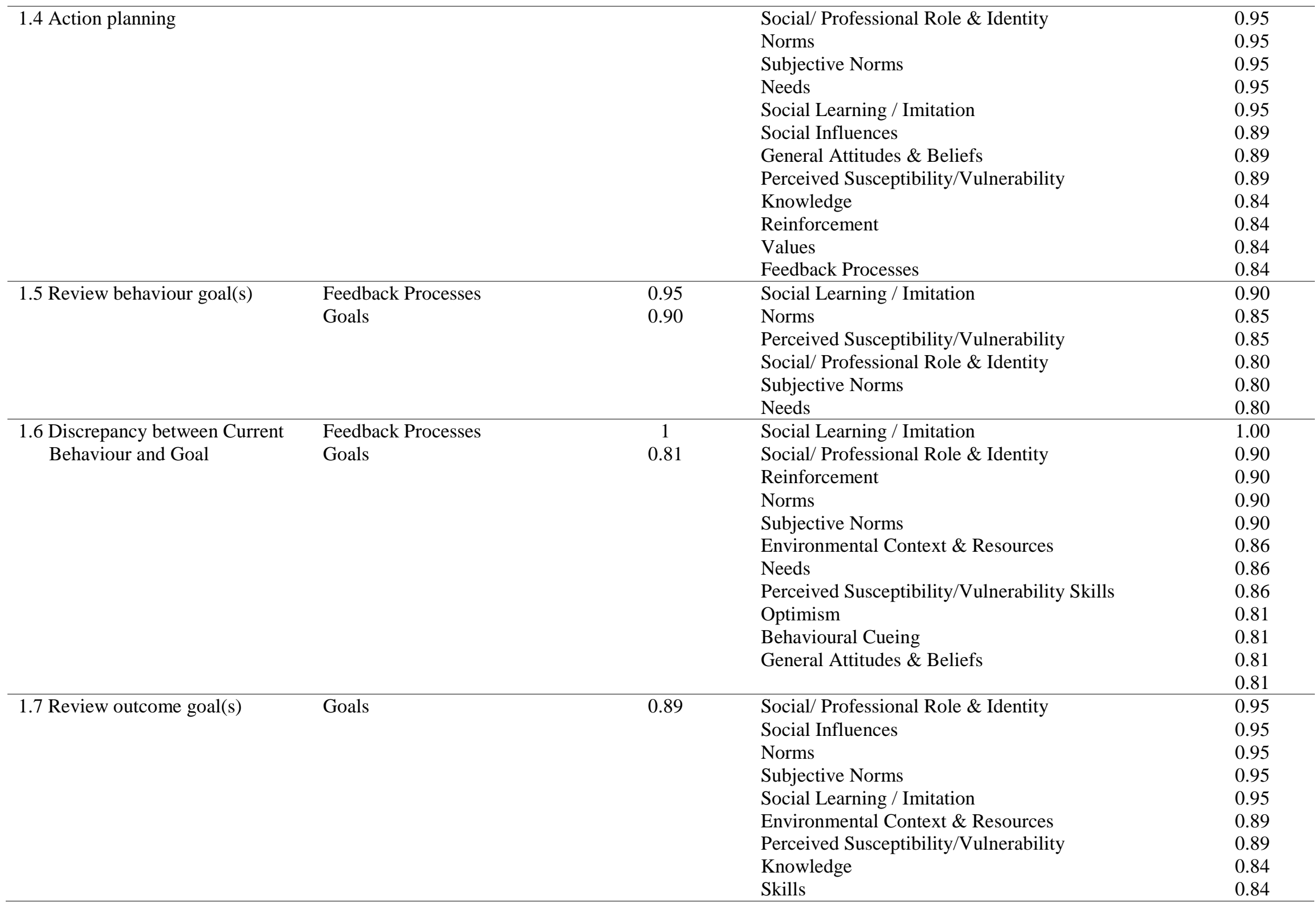




\begin{tabular}{|c|c|c|c|c|}
\hline & & & Needs & 0.84 \\
\hline & & & Behavioural Cueing & 0.84 \\
\hline \multirow[t]{5}{*}{ 1.8 Behavioural Contract } & \multirow[t]{5}{*}{ Intention } & \multirow[t]{5}{*}{0.80} & Social Learning / Imitation & 0.95 \\
\hline & & & Needs & 0.90 \\
\hline & & & Perceived Susceptibility/Vulnerability & 0.90 \\
\hline & & & Skills & 0.85 \\
\hline & & & Knowledge & 0.80 \\
\hline \multirow[t]{2}{*}{ 1.9 Commitment } & Intention & 0.84 & Skills & 0.84 \\
\hline & Motivation & 0.84 & Reinforcement & 0.84 \\
\hline \multirow{2}{*}{$\begin{array}{l}\text { 2.1 Monitoring of behaviour by } \\
\text { others without feedback }\end{array}$} & & & Needs & 0.89 \\
\hline & & & Optimism & 0.84 \\
\hline \multirow[t]{2}{*}{ 2.2 Feedback on behaviour } & \multirow[t]{2}{*}{ Feedback Processes } & \multirow[t]{2}{*}{0.95} & Needs & 0.84 \\
\hline & & & Social Learning/Imitation & 0.84 \\
\hline \multirow[t]{7}{*}{ 2.3 Self-monitoring of behaviour } & \multirow[t]{7}{*}{ Feedback Processes } & \multirow[t]{7}{*}{0.80} & Social Learning/Imitation & 0.95 \\
\hline & & & Norms & 0.90 \\
\hline & & & Subjective Norms & 0.90 \\
\hline & & & Social/ Professional Role \& Identity & 0.85 \\
\hline & & & General Attitudes \& Beliefs & 0.85 \\
\hline & & & Perceived Susceptibility/Vulnerability & 0.85 \\
\hline & & & Social Influences & 0.80 \\
\hline \multirow{9}{*}{$\begin{array}{l}\text { 2.4 Self-monitoring of outcome(s) } \\
\text { of behaviour }\end{array}$} & \multirow[t]{9}{*}{ Feedback Processes } & \multirow[t]{9}{*}{0.81} & Norms & 1 \\
\hline & & & Social Influences & 0.95 \\
\hline & & & Subjective Norms & 0.95 \\
\hline & & & Needs & 0.95 \\
\hline & & & Social Learning/Imitation & 0.95 \\
\hline & & & Social/ Professional Role \& Identity & 0.90 \\
\hline & & & Perceived Susceptibility/Vulnerability & 0.90 \\
\hline & & & Values & 0.86 \\
\hline & & & General Attitudes \& Beliefs & 0.81 \\
\hline \multirow{5}{*}{$\begin{array}{l}2.5 \text { Monitoring of outcomes of } \\
\text { behaviour without feedback }\end{array}$} & & & Needs & 0.95 \\
\hline & & & Social Learning/Imitation & 0.95 \\
\hline & & & Skills & 0.86 \\
\hline & & & Social/ Professional Role \& Identity & 0.86 \\
\hline & & & Optimism & 0.86 \\
\hline
\end{tabular}




\begin{tabular}{|c|c|c|c|c|}
\hline & & & $\begin{array}{l}\text { Memory, Attention, \& Decision Processes } \\
\text { Environmental Context \& Resources } \\
\text { Norms } \\
\text { Values } \\
\text { General Attitudes \& Beliefs }\end{array}$ & $\begin{array}{l}0.81 \\
0.81 \\
0.81 \\
0.81 \\
0.81\end{array}$ \\
\hline 2.6 Biofeedback & Feedback Processes & 0.89 & $\begin{array}{l}\text { Social/ Professional Role \& Identity } \\
\text { Norms } \\
\text { Subjective Norms } \\
\text { Social Learning/Imitation } \\
\text { Social Influences } \\
\text { Values }\end{array}$ & $\begin{array}{l}0.89 \\
0.89 \\
0.89 \\
0.89 \\
0.84 \\
0.84\end{array}$ \\
\hline $\begin{array}{l}\text { 2.7 Feedback on outcome(s) of } \\
\text { behaviour }\end{array}$ & Feedback Processes & 0.80 & $\begin{array}{l}\text { Subjective Norms } \\
\text { Social Learning/Imitation } \\
\text { Environmental Context \& Resources } \\
\text { Norms } \\
\text { Perceived Susceptibility/Vulnerability }\end{array}$ & $\begin{array}{l}0.80 \\
0.95 \\
0.90 \\
0.90 \\
0.85\end{array}$ \\
\hline 3.1 Social Support (unspecified) & Social Influences & 0.87 & $\begin{array}{l}\text { Skills } \\
\text { Perceived Susceptibility/Vulnerability }\end{array}$ & $\begin{array}{l}0.87 \\
0.82\end{array}$ \\
\hline 3.3 Social Support (emotional) & Emotion & 0.84 & Feedback Processes & 0.84 \\
\hline $\begin{array}{l}\text { 4.1 Instruction on how to perform } \\
\text { the behaviour }\end{array}$ & Skills & 0.86 & $\begin{array}{l}\text { Needs } \\
\text { Perceived Susceptibility/Vulnerability } \\
\text { Values } \\
\text { Emotion } \\
\text { Social/Professional Role \& Identity } \\
\text { Subjective Norms } \\
\text { Norms }\end{array}$ & $\begin{array}{l}0.90 \\
0.90 \\
0.87 \\
0.84 \\
0.82 \\
0.82 \\
0.81\end{array}$ \\
\hline 4.2 Information about Antecedents & $\begin{array}{l}\text { Knowledge } \\
\text { Behavioural Cueing }\end{array}$ & $\begin{array}{l}0.86 \\
0.81\end{array}$ & $\begin{array}{l}\text { Needs } \\
\text { Social/Professional Role \& Identity } \\
\text { Norms } \\
\text { Subjective Norms } \\
\text { Values } \\
\text { Feedback Processes } \\
\text { General Attitudes \& Beliefs }\end{array}$ & $\begin{array}{l}0.95 \\
0.90 \\
0.90 \\
0.90 \\
0.90 \\
0.90 \\
0.90\end{array}$ \\
\hline
\end{tabular}




\begin{tabular}{|c|c|c|c|c|}
\hline & & & $\begin{array}{l}\text { Skills } \\
\text { Self-image } \\
\text { Social Learning/Imitation } \\
\text { Optimism } \\
\text { Reinforcement } \\
\text { Social Influences } \\
\text { Attitude towards the Behaviour }\end{array}$ & $\begin{array}{l}0.86 \\
0.86 \\
0.86 \\
0.81 \\
0.81 \\
0.81 \\
0.81\end{array}$ \\
\hline $\begin{array}{l}5.1 \text { Information about Health } \\
\text { Consequences }\end{array}$ & $\begin{array}{l}\text { Beliefs about Consequences } \\
\text { Knowledge } \\
\text { Perceived Susceptibility and } \\
\text { Vulnerability }\end{array}$ & $\begin{array}{l}0.95 \\
0.89 \\
0.84\end{array}$ & $\begin{array}{l}\text { Reinforcement } \\
\text { Social Learning / Imitation } \\
\text { Skills } \\
\text { Optimism } \\
\text { Behavioural Regulation } \\
\text { Subjective Norms } \\
\text { Social/Professional Role \& Identity } \\
\text { Environmental Context \& Resources } \\
\text { Self-Image } \\
\text { Needs }\end{array}$ & $\begin{array}{l}0.95 \\
0.95 \\
0.89 \\
0.89 \\
0.89 \\
0.89 \\
0.84 \\
0.84 \\
0.84 \\
0.84\end{array}$ \\
\hline 5.2 Salience of Consequences & Beliefs about Consequences & 0.85 & $\begin{array}{l}\text { Skills } \\
\text { Social Learning/Imitation } \\
\text { Optimism } \\
\text { Needs } \\
\text { Social/Professional Role \& Identity } \\
\text { Beliefs about Capabilities }\end{array}$ & $\begin{array}{l}0.95 \\
0.90 \\
0.85 \\
0.85 \\
0.80 \\
0.80\end{array}$ \\
\hline $\begin{array}{l}\text { 5.3 Information about Social and } \\
\text { Environmental Consequences }\end{array}$ & $\begin{array}{l}\text { Beliefs about Consequences } \\
\text { Motivation }\end{array}$ & $\begin{array}{l}0.95 \\
0.86\end{array}$ & $\begin{array}{l}\text { Skills } \\
\text { Social Learning/Imitation } \\
\text { Behavioural Regulation } \\
\text { Feedback Processes } \\
\text { Beliefs about Capabilities } \\
\text { Optimism } \\
\text { Needs }\end{array}$ & $\begin{array}{l}1 \\
0.95 \\
0.90 \\
0.90 \\
0.86 \\
0.86 \\
0.81\end{array}$ \\
\hline $\begin{array}{l}\text { 5.4 Monitoring of emotional } \\
\text { consequences }\end{array}$ & Emotion & 0.80 & $\begin{array}{l}\text { Skills } \\
\text { Social/Professional Role \& Identity } \\
\text { Memory, Attention, \& Decision Processes } \\
\text { Norms } \\
\text { Subjective Norms } \\
\text { Social Learning/Imitation } \\
\text { Environmental Context \& Resources }\end{array}$ & $\begin{array}{l}0.95 \\
0.90 \\
0.90 \\
0.90 \\
0.90 \\
0.90 \\
0.85\end{array}$ \\
\hline
\end{tabular}




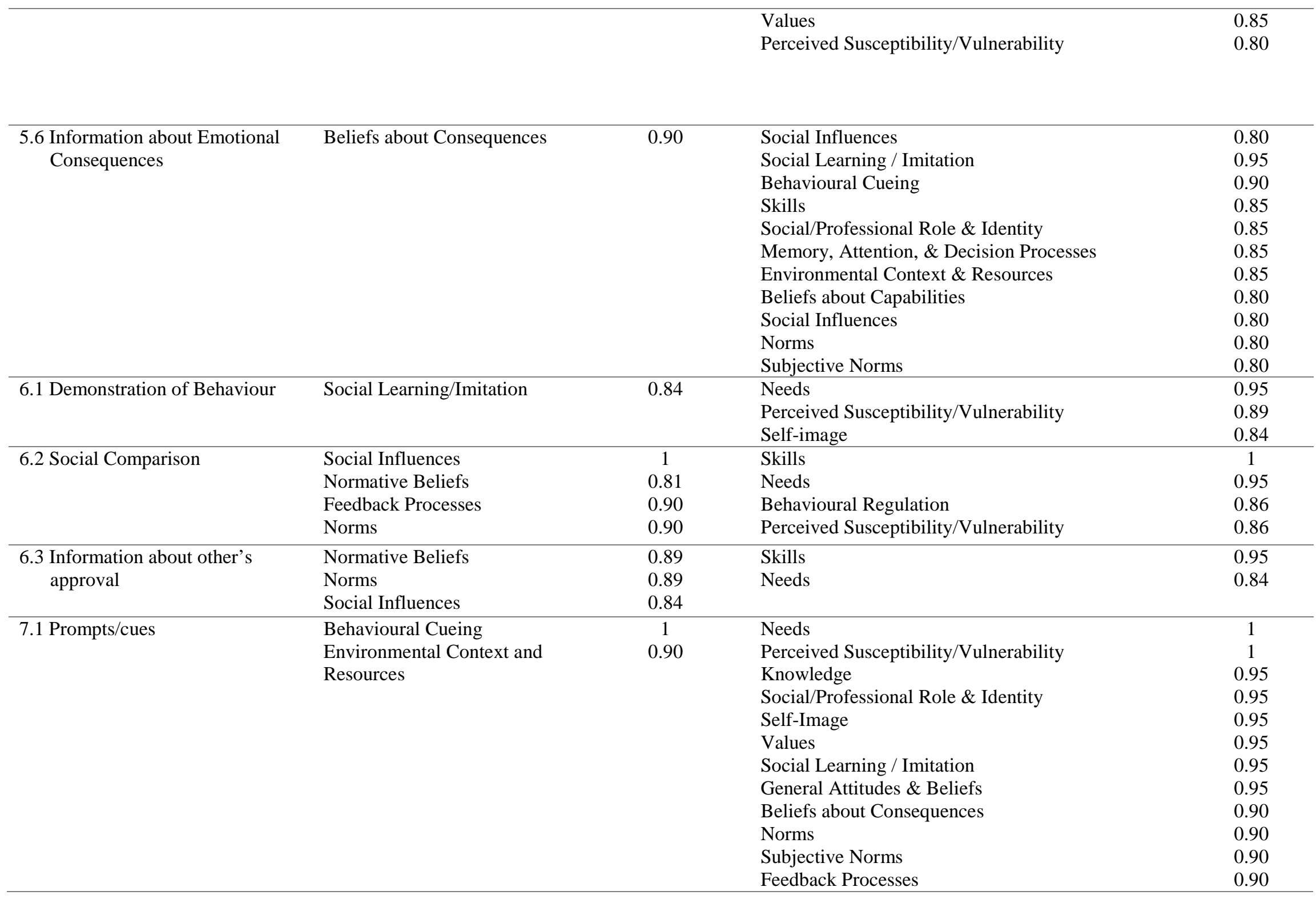




\begin{tabular}{|c|c|c|c|c|}
\hline & & & $\begin{array}{l}\text { Beliefs about Capabilities } \\
\text { Optimism } \\
\text { Attitude towards the Behaviour } \\
\text { Emotion }\end{array}$ & $\begin{array}{l}0.86 \\
0.86 \\
0.86 \\
0.81\end{array}$ \\
\hline 7.5 Remove aversive stimulus & $\begin{array}{l}\text { Environmental Context and } \\
\text { Resources }\end{array}$ & 0.90 & $\begin{array}{l}\text { Knowledge } \\
\text { Needs } \\
\text { Skills } \\
\text { Social/Professional Role \& Identity } \\
\text { Values } \\
\text { Subjective Norms } \\
\text { Self-Image } \\
\text { Perceived Susceptibility/Vulnerability } \\
\text { Norms } \\
\text { Feedback Processes } \\
\text { Social Learning / Imitation }\end{array}$ & $\begin{array}{l}1 \\
1 \\
0.95 \\
0.95 \\
0.90 \\
0.86 \\
0.86 \\
0.86 \\
0.81 \\
0.81 \\
0.81\end{array}$ \\
\hline 8.1 Behavioural Practice/Rehearsal & $\begin{array}{l}\text { Skills } \\
\text { Beliefs about Capabilities }\end{array}$ & $\begin{array}{l}0.95 \\
0.86\end{array}$ & $\begin{array}{l}\text { Norms } \\
\text { Needs } \\
\text { Values } \\
\text { Social/Professional Role \& Identity } \\
\text { Subjective Norms } \\
\text { Social Influences } \\
\text { Social Learning / Imitation } \\
\text { Perceived Susceptibility/Vulnerability } \\
\text { General Attitudes \& Beliefs }\end{array}$ & $\begin{array}{l}0.95 \\
0.95 \\
0.95 \\
0.90 \\
0.90 \\
0.86 \\
0.86 \\
0.86 \\
0.81\end{array}$ \\
\hline 8.2 Behaviour Substitution & & & $\begin{array}{l}\text { Needs } \\
\text { Social/Professional Role \& Identity } \\
\text { Social Learning / Imitation } \\
\text { Social Influences } \\
\text { Emotion } \\
\text { Norms } \\
\text { Subjective Norms } \\
\text { General Attitudes \& Beliefs } \\
\text { Self-Image }\end{array}$ & $\begin{array}{l}1 \\
0.95 \\
0.95 \\
0.89 \\
0.89 \\
0.89 \\
0.89 \\
0.89 \\
0.84\end{array}$ \\
\hline
\end{tabular}




\begin{tabular}{|c|c|c|c|c|}
\hline 8.3 Habit Formation & Behavioural Cueing & 0.85 & $\begin{array}{l}\text { Perceived Susceptibility/Vulnerability } \\
\text { Needs } \\
\text { General Attitudes \& Beliefs } \\
\text { Knowledge } \\
\text { Optimism } \\
\text { Norms } \\
\text { Values } \\
\text { Feedback Processes }\end{array}$ & $\begin{array}{l}0.90 \\
0.85 \\
0.85 \\
0.80 \\
0.80 \\
0.80 \\
0.80 \\
0.80\end{array}$ \\
\hline 8.4 Habit Reversal & Skills & 0.84 & Needs & 0.84 \\
\hline $\begin{array}{l}\text { 8.6 Generalisation of the Target } \\
\text { Behaviour }\end{array}$ & & & $\begin{array}{l}\text { Needs } \\
\text { Perceived Susceptibility/Vulnerability }\end{array}$ & $\begin{array}{l}0.89 \\
0.84\end{array}$ \\
\hline 8.7 Graded Tasks & $\begin{array}{l}\text { Beliefs about Capabilities } \\
\text { Skills }\end{array}$ & $\begin{array}{l}0.90 \\
0.81\end{array}$ & $\begin{array}{l}\text { Social Influences } \\
\text { Norms } \\
\text { Needs } \\
\text { Subjective Norms } \\
\text { Values } \\
\text { Social/Professional Role \& Identity } \\
\text { Social Learning / Imitation } \\
\text { Perceived Susceptibility/Vulnerability } \\
\text { Knowledge } \\
\text { Behavioural Cueing }\end{array}$ & $\begin{array}{l}1 \\
1 \\
1 \\
0.95 \\
0.95 \\
0.86 \\
0.86 \\
0.86 \\
0.81 \\
0.81\end{array}$ \\
\hline 9.1 Credible Source & & & $\begin{array}{l}\text { Skills } \\
\text { Needs } \\
\text { Reinforcement }\end{array}$ & $\begin{array}{l}0.89 \\
0.89 \\
0.84\end{array}$ \\
\hline 9.2 Pros and Cons & $\begin{array}{l}\text { Beliefs about Consequences } \\
\text { Motivation } \\
\text { Attitude towards the } \\
\text { Behaviour }\end{array}$ & $\begin{array}{l}0.90 \\
0.86 \\
0.81\end{array}$ & $\begin{array}{l}\text { Social Learning / Imitation } \\
\text { Skills } \\
\text { Behavioural Cueing } \\
\text { Social/Professional Role \& Identity } \\
\text { Self-Image } \\
\text { Needs }\end{array}$ & $\begin{array}{l}1 \\
0.90 \\
0.86 \\
0.81 \\
0.81 \\
0.81\end{array}$ \\
\hline
\end{tabular}




\begin{tabular}{|c|c|c|c|c|}
\hline $\begin{array}{l}\text { 9.3 Comparative Imagining of } \\
\text { Future Outcomes }\end{array}$ & $\begin{array}{l}\text { Beliefs about Consequences } \\
\text { Intention } \\
\text { Motivation }\end{array}$ & $\begin{array}{c}1 \\
0.81 \\
0.86\end{array}$ & $\begin{array}{l}\text { Skills } \\
\text { Social Learning / Imitation } \\
\text { Reinforcement } \\
\text { Norms } \\
\text { Environment } \\
\text { Social Influences } \\
\text { Social/Professional Role \& Identity }\end{array}$ & $\begin{array}{l}1 \\
0.95 \\
0.90 \\
0.90 \\
0.86 \\
0.86 \\
0.81\end{array}$ \\
\hline $\begin{array}{l}10.1 \text { Material Incentive } \\
\text { (behaviour) }\end{array}$ & $\begin{array}{l}\text { Reinforcement } \\
\text { Motivation }\end{array}$ & $\begin{array}{l}0.95 \\
0.84\end{array}$ & Social Learning / Imitation & 0.84 \\
\hline 10.2 Material Reward (behaviour) & Reinforcement & 0.89 & $\begin{array}{l}\text { Social/Professional Role \& Identity } \\
\text { Social Learning / Imitation } \\
\text { Perceived Susceptibility/Vulnerability } \\
\text { Knowledge } \\
\text { Skills } \\
\text { Memory, Attention, \& Decision Processes } \\
\text { Social Influences } \\
\text { Norms } \\
\text { Subjective Norms } \\
\text { Self-Image } \\
\text { Optimism }\end{array}$ & $\begin{array}{l}0.95 \\
0.95 \\
0.95 \\
0.89 \\
0.89 \\
0.89 \\
0.89 \\
0.89 \\
0.89 \\
0.89 \\
0.84\end{array}$ \\
\hline 10.3 Non-specific Reward & $\begin{array}{l}\text { Reinforcement } \\
\text { Motivation }\end{array}$ & $\begin{array}{l}0.95 \\
0.84\end{array}$ & $\begin{array}{l}\text { Social/Professional Role \& Identity } \\
\text { Subjective Norms } \\
\text { Self-image } \\
\text { Needs } \\
\text { Values } \\
\text { Social Learning / Imitation } \\
\text { Perceived Susceptibility/Vulnerability } \\
\text { Optimism } \\
\text { Social Influences } \\
\text { Behavioural Regulation } \\
\text { Norms } \\
\text { Knowledge } \\
\text { Skills } \\
\text { Feedback Processes }\end{array}$ & $\begin{array}{l}0.95 \\
0.95 \\
0.95 \\
0.95 \\
0.95 \\
0.95 \\
0.95 \\
0.89 \\
0.89 \\
0.89 \\
0.89 \\
0.84 \\
0.84 \\
0.84\end{array}$ \\
\hline
\end{tabular}




\begin{tabular}{|c|c|c|c|c|}
\hline \multirow[t]{7}{*}{ 10.4 Social Reward } & Social Comparison & 0.95 & Perceived Susceptibility/Vulnerability & 1 \\
\hline & Motivation & 0.81 & Skills & 0.95 \\
\hline & & & Memory, Attention, \& Decision Processes & 0.90 \\
\hline & & & Social Learning / Imitation & 0.90 \\
\hline & & & Knowledge & 0.86 \\
\hline & & & Needs & 0.86 \\
\hline & & & General Attitudes \& Beliefs & 0.86 \\
\hline \multirow[t]{11}{*}{ 10.6 Non-specific Incentive } & & & Skills & 0.95 \\
\hline & & & Social/Professional Role \& Identity & 0.95 \\
\hline & & & Social Learning / Imitation & 0.95 \\
\hline & & & Perceived Susceptibility/Vulnerability & 0.95 \\
\hline & & & Knowledge & 0.89 \\
\hline & & & Optimism & 0.89 \\
\hline & & & Norms & 0.89 \\
\hline & & & Subjective Norms & 0.89 \\
\hline & & & Self-Image & 0.89 \\
\hline & & & Beliefs about Capabilities & 0.84 \\
\hline & & & Values & 0.84 \\
\hline \multirow[t]{12}{*}{10.8 Incentive (outcome) } & Intention & 0.95 & Skills & 1 \\
\hline & Beliefs about Consequences & 0.90 & Perceived Susceptibility/Vulnerability & 1 \\
\hline & Reinforcement & 0.90 & Social/Professional Role \& Identity & 0.95 \\
\hline & & & Self -Image & 0.95 \\
\hline & & & Social Learning / Imitation & 0.95 \\
\hline & & & Subjective Norms & 0.90 \\
\hline & & & Social Influences & 0.86 \\
\hline & & & Norms & 0.86 \\
\hline & & & Values & 0.86 \\
\hline & & & Beliefs about Capabilities & 0.81 \\
\hline & & & Memory, Attention, \& Decision Processes & 0.81 \\
\hline & & & General Attitudes \& Beliefs & 0.81 \\
\hline
\end{tabular}




\begin{tabular}{|c|c|c|c|c|}
\hline \multirow{12}{*}{ 10.10 Reward (outcome) } & Reinforcement & 0.90 & Skills & 1 \\
\hline & Motivation & 0.90 & Perceived Susceptibility/Vulnerability & 1 \\
\hline & Beliefs about Consequences & 0.86 & Social/Professional Role \& Identity & 0.95 \\
\hline & & & Self -Image & 0.95 \\
\hline & & & Social Learning / Imitation & 0.95 \\
\hline & & & Subjective Norms & 0.90 \\
\hline & & & Social Influences & 0.86 \\
\hline & & & Norms & 0.86 \\
\hline & & & Values & 0.86 \\
\hline & & & Beliefs about Capabilities & 0.81 \\
\hline & & & Memory, Attention, \& Decision Processes & 0.81 \\
\hline & & & General Attitudes \& Beliefs & 0.81 \\
\hline \multirow[t]{7}{*}{ 11.1 Pharmacological Support } & & & Skills & 0.95 \\
\hline & & & Subjective Norms & 0.95 \\
\hline & & & Values & 0.95 \\
\hline & & & Feedback Processes & 0.95 \\
\hline & & & Social Learning / Imitation & 0.95 \\
\hline & & & Social/Professional Role \& Identity & 0.89 \\
\hline & & & Norms & 0.89 \\
\hline \multirow[t]{8}{*}{ 11.2 Reduce Negative Emotions } & Emotion & 0.95 & Subjective Norms & 0.95 \\
\hline & Behavioural Regulation & 0.90 & Values & 0.95 \\
\hline & & & Social/Professional Role \& Identity & 0.90 \\
\hline & & & Norms & 0.90 \\
\hline & & & Feedback Processes & 0.90 \\
\hline & & & Social Learning / Imitation & 0.90 \\
\hline & & & Knowledge & 0.86 \\
\hline & & & Behavioural Cueing & 0.86 \\
\hline \multirow[t]{10}{*}{ 11.3 Conserving Mental Resources } & Memory, Attention \& & 1 & Social/Professional Role \& Identity & 1 \\
\hline & Decision Processes & & Norms & 1 \\
\hline & & & Subjective Norms & 1 \\
\hline & & & Perceived Susceptibility/Vulnerability & 1 \\
\hline & & & Social Influences & 0.95 \\
\hline & & & Needs & 0.95 \\
\hline & & & Values & 0.95 \\
\hline & & & Feedback Processes & 0.95 \\
\hline & & & Social Learning / Imitation & 0.95 \\
\hline & & & Self-Image & 0.90 \\
\hline
\end{tabular}




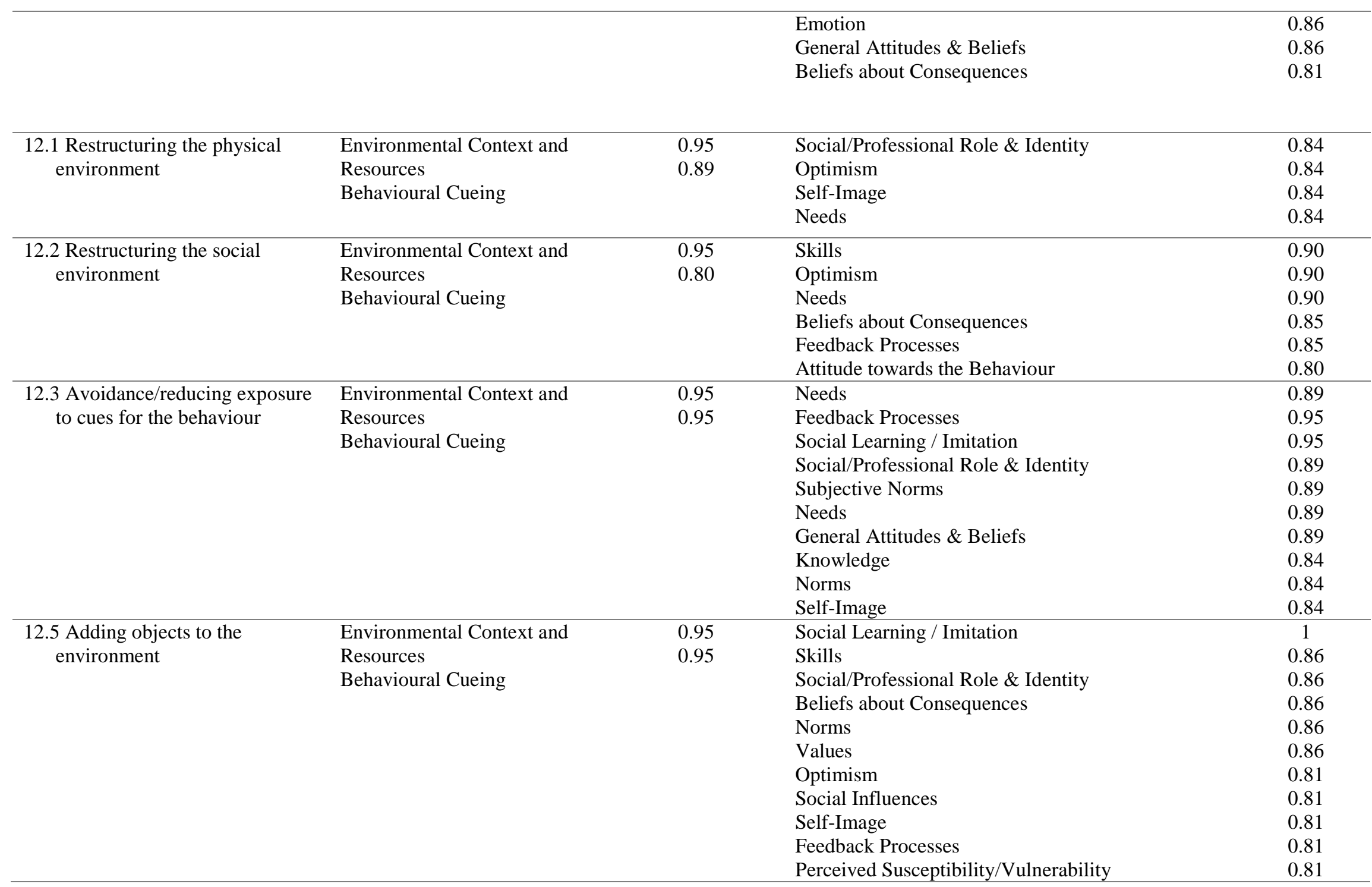




\begin{tabular}{|c|c|c|c|c|}
\hline \multicolumn{3}{|l|}{ 12.6 Body Changes } & Norms & 1 \\
\hline & & & Subjective Norms & 0.95 \\
\hline & & & Social Learning / Imitation & 0.95 \\
\hline & & & Knowledge & 0.90 \\
\hline & & & Values & 0.90 \\
\hline & & & Social/Professional Role \& Identity & 0.86 \\
\hline & & & Social Influences & 0.86 \\
\hline & & & Memory, Attention, \& Decision Processes & 0.81 \\
\hline & & & Feedback Processes & 0.81 \\
\hline \multirow{3}{*}{$\begin{array}{l}\text { 13.1 Identification of self as role } \\
\text { model }\end{array}$} & & & Skills & 0.80 \\
\hline & & & Optimism & 0.80 \\
\hline & & & Needs & 0.80 \\
\hline \multirow[t]{8}{*}{ 13.2 Framing/Reframing } & Attitude towards the & 0.81 & Skills & 0.95 \\
\hline & Behaviour & & Needs & 0.95 \\
\hline & & & Social/Professional Role \& Identity & 0.90 \\
\hline & & & Social Learning / Imitation & 0.90 \\
\hline & & & Reinforcement & 0.86 \\
\hline & & & Behavioural Cueing & 0.86 \\
\hline & & & Environmental Context \& Resources & 0.81 \\
\hline & & & Feedback Processes & 0.81 \\
\hline \multirow[t]{3}{*}{ 14.1 Behaviour cost } & Reinforcement & 0.95 & Skills & 0.84 \\
\hline & & & Social/Professional Role \& Identity & 0.84 \\
\hline & & & Subjective Norms & 0.84 \\
\hline \multirow{9}{*}{$\begin{array}{l}\text { 15.1 Verbal persuasion about } \\
\text { capability }\end{array}$} & Beliefs about Capabilities & 1 & Needs & 0.95 \\
\hline & & & Social/Professional Role \& Identity & 0.90 \\
\hline & & & Memory, Attention, \& Decision Processes & 0.90 \\
\hline & & & Social Learning / Imitation & 0.90 \\
\hline & & & Norms & 0.86 \\
\hline & & & Values & 0.86 \\
\hline & & & General Attitudes \& Beliefs & 0.86 \\
\hline & & & Perceived Susceptibility/Vulnerability & 0.86 \\
\hline & & & Feedback Processes & 0.81 \\
\hline
\end{tabular}




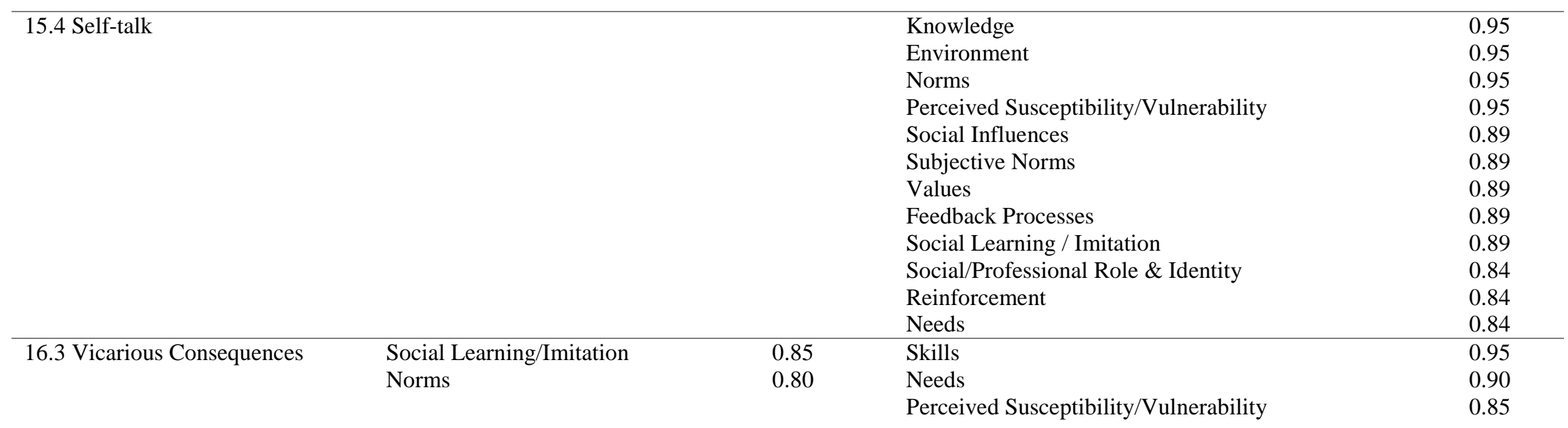

Note. The table above indicates mechanisms of action for which $80 \%$ or more of experts responded 'Definitely Yes' in response to the question, 'When [BCT X] works, does it work through changing [Mechanism of Action Y]?', or 'Definitely No'. The proportion of experts selecting a response option is indicated, with the number of experts rating each link varying by BCT. 
Table 2

Agreed Links between Behaviour Change Techniques and Mechanisms of Action (by Mechanism of Action)

\begin{tabular}{lccc}
\hline \multirow{2}{*}{ Mechanism of Action } & 'Definitely Yes' Linked & $\begin{array}{c}\text { Behaviour Change Technique } \\
\text { Proportion } \\
\text { of Experts }\end{array}$ & $\begin{array}{c}\text { 'Definitely No' Not Linked } \\
\text { of Experts }\end{array}$ \\
\cline { 2 - 3 } & & 0.86 \\
\hline Knowledge & 4.2 Information about Antecedents & 0.89
\end{tabular}

8.1 Behavioural Practice/Rehearsal

8.4 Habit Reversal

0.84

8.7 Graded Tasks

0.81

Social/Professional Role and Identity
1.1 Goal Setting (Behaviour)

1.2 Problem Solving
0.90

0.90

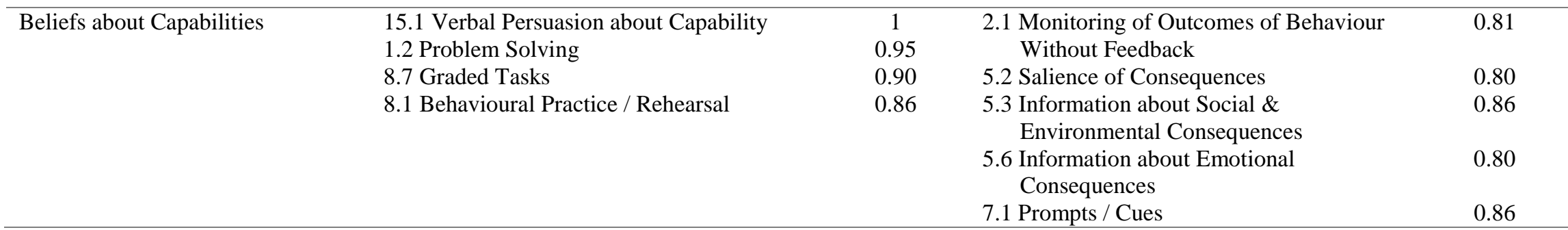


Optimism

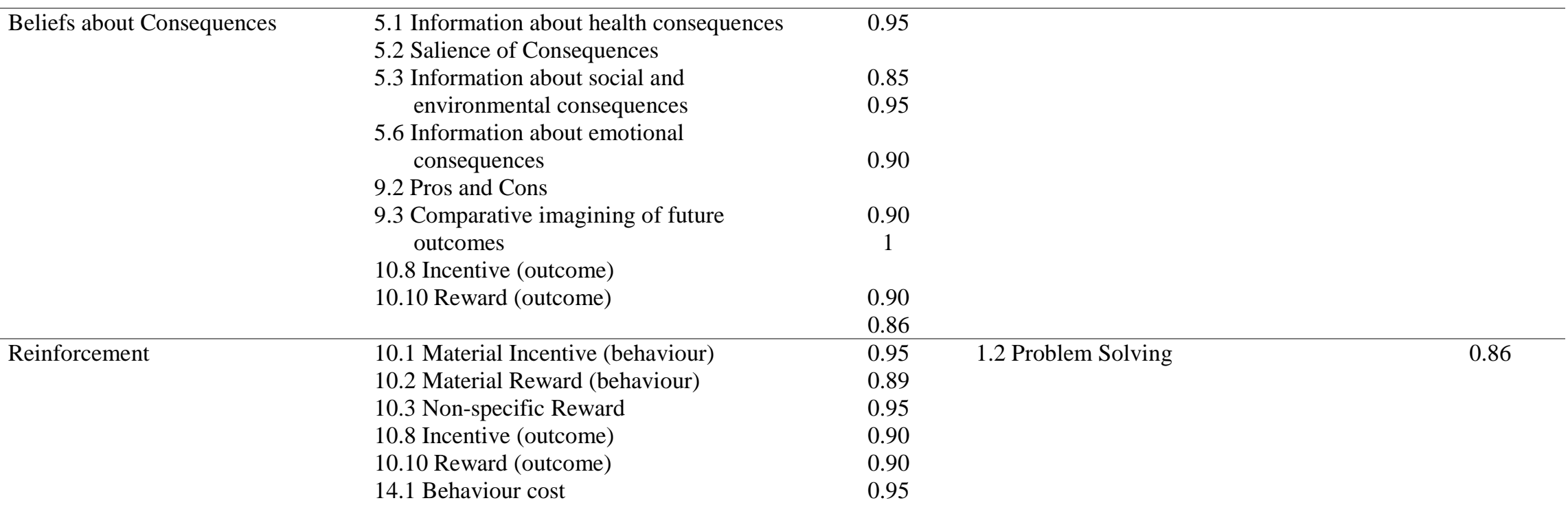




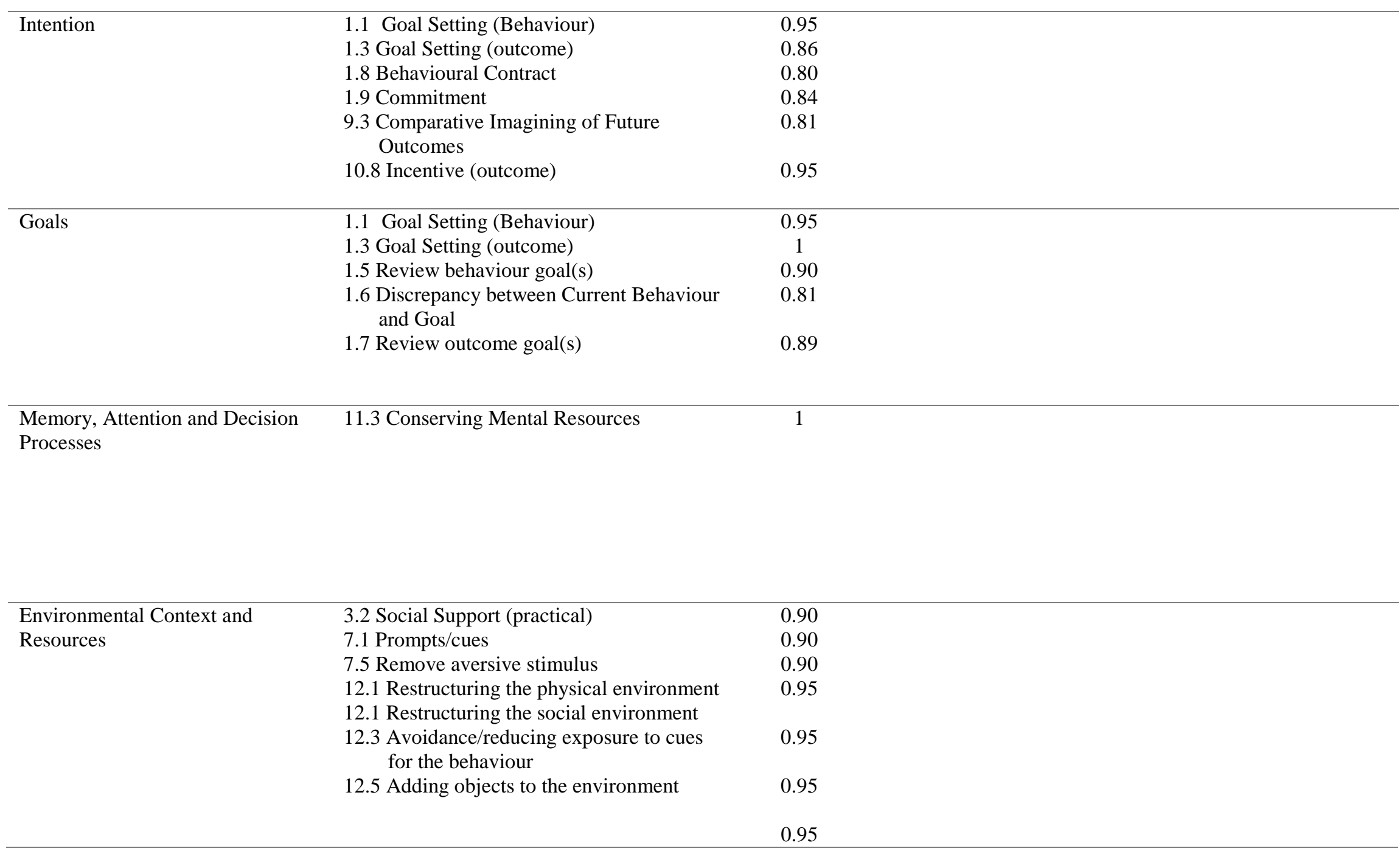




\begin{tabular}{|c|c|c|c|c|}
\hline Social Influences & $\begin{array}{l}\text { 3.1 Social Support (unspecified) } \\
\text { 3.2 Social Support (practical) } \\
\text { 6.2 Social Comparison } \\
\text { 6.3 Information about other’s approval }\end{array}$ & $\begin{array}{c}0.87 \\
0.90 \\
1 \\
0.84\end{array}$ & $\begin{array}{l}\text { 1.1 Goal Setting (Behaviour) } \\
\text { 1.2 Problem Solving } \\
\text { 5.6 Information about emotional } \\
\text { consequences }\end{array}$ & $\begin{array}{l}0.80 \\
0.81 \\
0.80\end{array}$ \\
\hline Emotion & $\begin{array}{l}\text { 3.3 Social Support (emotional) } \\
\text { 5.4 Monitoring of emotional consequences } \\
\text { 11.2 Reduce Negative Emotions }\end{array}$ & $\begin{array}{l}0.84 \\
0.80 \\
0.95\end{array}$ & 1.2 Problem Solving & 0.81 \\
\hline Behavioural Regulation & $\begin{array}{l}\text { 1.3 Problem Solving } \\
\text { 11.2 Reduce Negative Emotions }\end{array}$ & $\begin{array}{c}1 \\
0.90\end{array}$ & & \\
\hline Norms & $\begin{array}{l}\text { 6.2 Social Comparison } \\
\text { 6.3 Information about other's approval } \\
\text { 16.3 Vicarious Consequences }\end{array}$ & $\begin{array}{l}0.90 \\
0.89 \\
0.80\end{array}$ & 1.2 Problem Solving & 0.95 \\
\hline
\end{tabular}




\begin{tabular}{|c|c|c|}
\hline Motivation & $\begin{array}{l}\text { 1.1 Goal Setting (Behaviour) } \\
\text { 1.9 Commitment } \\
\text { 5.3 Information about Social and } \\
\quad \text { Environmental Consequences } \\
\text { 9.2 Pros and Cons } \\
\text { 9.3 Comparative Imagining of Future } \\
\quad \text { Outcomes } \\
\text { 10.1 Material Incentive (behaviour) } \\
\text { 10.3 Non-specific Reward } \\
\text { 10.4 Social Reward } \\
\text { 10.10 Reward (outcome) }\end{array}$ & $\begin{array}{l}0.80 \\
0.84 \\
0.86 \\
\\
0.86 \\
0.86 \\
\\
0.84 \\
0.84 \\
0.81 \\
0.90\end{array}$ \\
\hline Self-Image & 13.1 Identification of self as role model & 0.90 \\
\hline
\end{tabular}


1.2 Problem Solving

2.1 Monitoring of behaviour by others

without feedback

12.3 Avoidance / Reducing Exposure to

Cues for the Behaviour

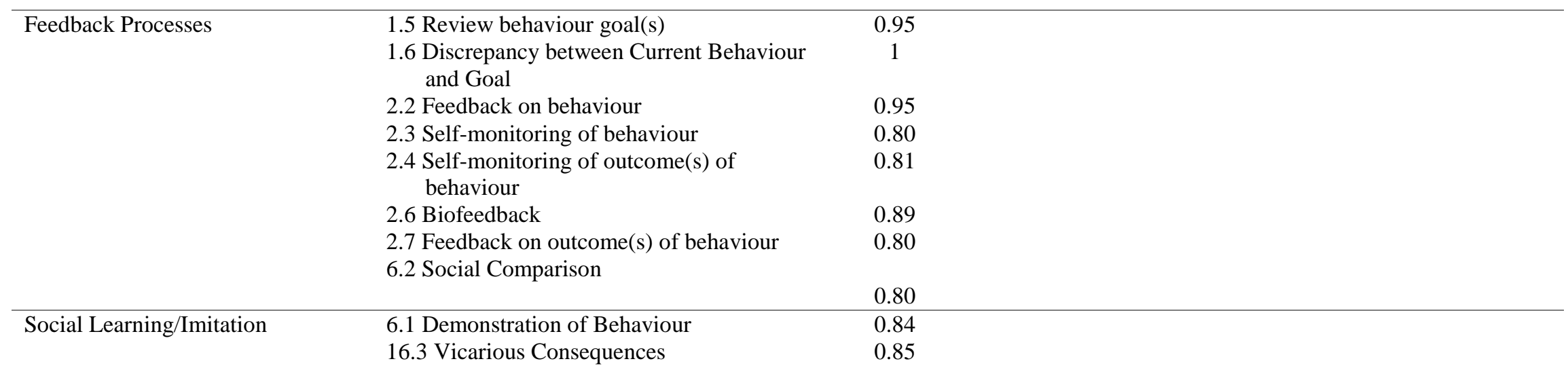




\begin{tabular}{|c|c|c|}
\hline \multirow[t]{7}{*}{ Behavioural Cueing } & 4.2 Information about Antecedents & 0.81 \\
\hline & 7.1 Prompts/cues & 1 \\
\hline & 8.3 Habit Formation & 0.85 \\
\hline & 12.1 Restructuring the physical environment & 0.85 \\
\hline & 12.1 Restructuring the social environment & \\
\hline & $\begin{array}{l}\text { 12.3 Avoidance/reducing exposure to cues } \\
\text { for the behaviour }\end{array}$ & 0.80 \\
\hline & 12.5 Adding objects to the environment & 0.95 \\
\hline
\end{tabular}

General Attitude \& Beliefs

1.2 Problem Solving

0.81

Perceived Susceptibility \&

5.1 Information about Health Consequences

0.84

1.1 Goal Setting (Behaviour)

0.90

Vulnerability

Note. The table above indicates mechanisms of action for which $80 \%$ or more of experts responded 'Definitely Yes' in response to the question, 'When [BCT X] works, does it work through changing [Mechanism of Action Y]?', or 'Definitely No'. The proportion of experts selecting a response option is indicated, with the number of experts rating each link varying by BCT. 